Review Article

\title{
Placental Evolution within the Supraordinal Clades of Eutheria with the Perspective of Alternative Animal Models for Human Placentation
}

\author{
Andrea Mess \\ Department of Surgery, Faculty of Veterinary Medicine and Animal Science, University of Sao Paulo (FMVZ-USP), \\ Avenida Prof. Dr. Orlando Marques de Paiva 87, 05508-270 Sao Paulo, SP, Brazil \\ Correspondence should be addressed to Andrea Mess; drandrmss@aol.com
}

Received 15 June 2014; Accepted 22 September 2014; Published 23 October 2014

Academic Editor: Hong-Bo Zhao

Copyright (C) 2014 Andrea Mess. This is an open access article distributed under the Creative Commons Attribution License, which permits unrestricted use, distribution, and reproduction in any medium, provided the original work is properly cited.

\begin{abstract}
Here a survey of placental evolution is conducted. Placentation is a key factor for the evolution of placental mammals that had evolved an astonishing diversity. As a temporary organ that does not allow easy access, it is still not well understood. The lack of data also is a restriction for better understanding of placental development, structure, and function in the human. Animal models are essential, because experimental access to the human placenta is naturally restricted. However, there is not a single ideal model that is entirely similar to humans. It is particularly important to establish other models than the mouse, which is characterised by a short gestation period and poorly developed neonates that may provide insights only for early human pregnancy. In conclusion, current evolutionary studies have contributed essentially to providing a pool of experimental models for recent and future approaches that may also meet the requirements of a long gestation period and advanced developmental status of the newborn in the human. Suitability and limitations of taxa as alternative animal models are discussed. However, further investigations especially in wildlife taxa should be conducted in order to learn more about the full evolutionary plasticity of the placenta system.
\end{abstract}

\section{Introduction}

Evolution of the placental system is a key feature of placental mammals or Eutheria. It was already present in their ancient condition (stem species pattern) and had evolved an astonishing diversity following the group's radiation during the Tertiary [1-8]. Indeed, both their chorioallantoic and yolk sac placentas are regarded as most diverse organs [4, 9-13]. This diversity affects structural and functional aspects such as trophoblast invasion, the establishment of the fetomaternal interface, immune tolerance, and exchange processes. Significant variations occur also in gene expression patterns. About 3000 genes are specifically expressed in eutherian placentas, associated with gene duplications, specifically expressed genes, and a high percentage of retroviral genes adapted for placental functions [14-18]. However, as a temporary organ that does not allow easy access to structure and function, an essential lack in understanding the interaction on various levels remained and placentation was dramatically underrepresented in the traditional surveys on the evolutionary history of mammals. Fortunately, for various reasons the situation has been improved to some degree in the last couple of years.

1.1. Evolutionary Developmental Biology. First, due to the rise of the broad field of evolutionary developmental biology that focuses on biological innovations and their biological genesis $[19,20]$, studies on developmental systems and their evolution under an organismic perspective gained more attention than before. Morphology always emphasized that organisms are developing systems and, thus, became an important kernel for such approaches [20].

1.2. Comparative Placentation. Second-probably as consequence-comparative placentation underwent some boom in the field of placental research and enlarged the basis of knowledge [21-25]. Thus, several taxa including rare or wildlife species have been studied by means of histology and modern methods like immunohistochemistry or proper fine structural investigations by electron microscopy. Among 
them are nonmurine rodents native to South America and Africa [26-40], as was shown by Figure 2, bats [41-43], anteaters and armadillos [44, 45], and some other taxa [46-51]. Also, there were several promising attempts to reinvestigate historical histological material from museum collections such as neotropical primates [52] or great apes [53-56] in order to answer open questions.

1.3. Molecular Phylogeny. Third, progress on the molecular phylogeny that leads to a completely new system of the higher-level relationships of mammals offers objective clues towards revealing the evolutionary history of the placental system. First surveys in that regard focused on only few but important characters such as the nature of the fetomaternal barrier [2, 3]. Starting from that, larger samples of more taxa and characters have been taken into account. We [4] published the first evolutionary reconstruction of 21 characters associated with placentation, the fetal membranes, and the female reproductive tract. The analysis was based on a preexisting hypothesis of eutherian interordinal relationships and the tracing of character evolution was done by applying the computer program MacClade. This analysis provided a comprehensive interpretation of the stem species pattern of Eutheria and argued that the ancestral condition was mostly preserved in the basal nodes of the group. Interestingly, a character transformation resulted in the stem lineage of Afrotheria [57], representing the first morphological support for this novel taxon. Later, other studies dealt with similar and other characters $[6,58-60]$ and included aspects of behavior and evolutionary traits $[8,15,61-66]$. Despite interesting progress, particularly the interhaemal barrier as the feature which attracted most interest differed in the interpretation of ancestral or derived conditions, mainly because the published studies were based on different taxa sampling or rooting of the respected trees [5]. However, since even most recent systematic approaches resulted in opposite conclusions about the basic nodes of Eutheria [67], this issue is still far from being resolved.

1.4. Animal Models. Finally, the field of animal models for human placentation, which was a key topic in placental research in the last couple of years, has stimulated interest in regard to placental development of laboratory and other mammalian species [68-71]. Despite its crucial role in reproduction, the placenta is one of the least understood human organs [72]. Animal models are essential to compensate for restricted experimental access to the human placenta. It seemed to be particularly important to establish other models than the mouse, which is characterised by a very short gestation period and poorly developed neonates that may provide insights in comparison to early human pregnancy, but not to the requirements of a long gestation and advanced developmental status of the newborn [71]. Thus, authors argued that attention should be directed away from the mouse and towards other and more relevant models in order to resolve future applications that cannot well be resolved with the existing models [71]. Zoological and evolutionary investigations are essential to improve the understanding of the full range of placental plasticity and to establish a pool of potential model species to experimentally investigate specific questions in relation to human placentation.

1.5. Gasps and Goals. However, most recent activities in the field of placentation are focusing more and more on molecular aspects, mostly dealing with animals that can be easily maintained under laboratory conditions. In contrast, it became difficult to publish data on placental structure or function under comparative and evolutionary perspectives. One could comprehend that the challenging interests may be followed by the oblivion of comparative placentation. Herewith a survey of placental evolution in the higher systematic clades of placental mammals will be conducted with special reference to the suitability and limitations of members as potential animal models for human placentation. In particular, the fetomaternal contact zone in the chorioallantoic placenta and its developmental establishment as well as yolk sac placentation are on focus.

\section{Systematics}

Vertebrates represent a major group of animals that originated in water habitats and then evolved to terrestrial life styles. In particular, Amniota are the most successful and diverse group of land vertebrates or tetrapods, characterised by the establishment of additional fetal membranes that facilitated reproduction independent from aquatic habitats $[7,73]$. Groups such as mammals, birds, and other sauropsids evolved by evolutionary radiations within amniotes. Mammalia was systematically divided into the oviparous (egg-laying) Monotremata on the one hand as well as the viviparous Metatheria (marsupials) and Eutheria (placental mammals) on the other $[73,74]$. However, only Eutheria developed a remarkable diversity with more than 4000 extant species, whereas the two other groups contain only about 3 and 350 species, respectively [75].

For Eutheria or placental mammals, the analysis of molecular data sets had led to a revolution in phylogeny and revealed new higher-level relationships with four superordinal clades for extant species (Figure 1). These are the novel clade Afrotheria (elephants, manatees, hyraxes, aardvark, elephant shrews, tenrecs) that originated on the African continent, Xenarthra (sloths, anteaters, armadillos) that had their main distribution area in South America, Laurasiatheria (carnivores, Cetartiodactyla, horses, pangolins, bats, Eulipotyphla) that have mainly evolved on the Northern continents, and finally Euarchontoglires (rodents, lagomorphs, primates, tree shrews, flying lemurs) that evolved more independently from the continent's history [76-83]. It is a peculiar strength of the molecular classification that most orders of the previous or historical classifications, which were based on morphological criteria, resulted as stable [84]. Only two exceptions occur. The new order Cetartiodactyla includes whales and dolphins (formerly Cetacea) within the even-toed ungulates (formerly Artiodactyla), which is not much in conflict with the traditional system that regarded them as close relatives [85]. What is more, Cetartiodactyla is now supported 


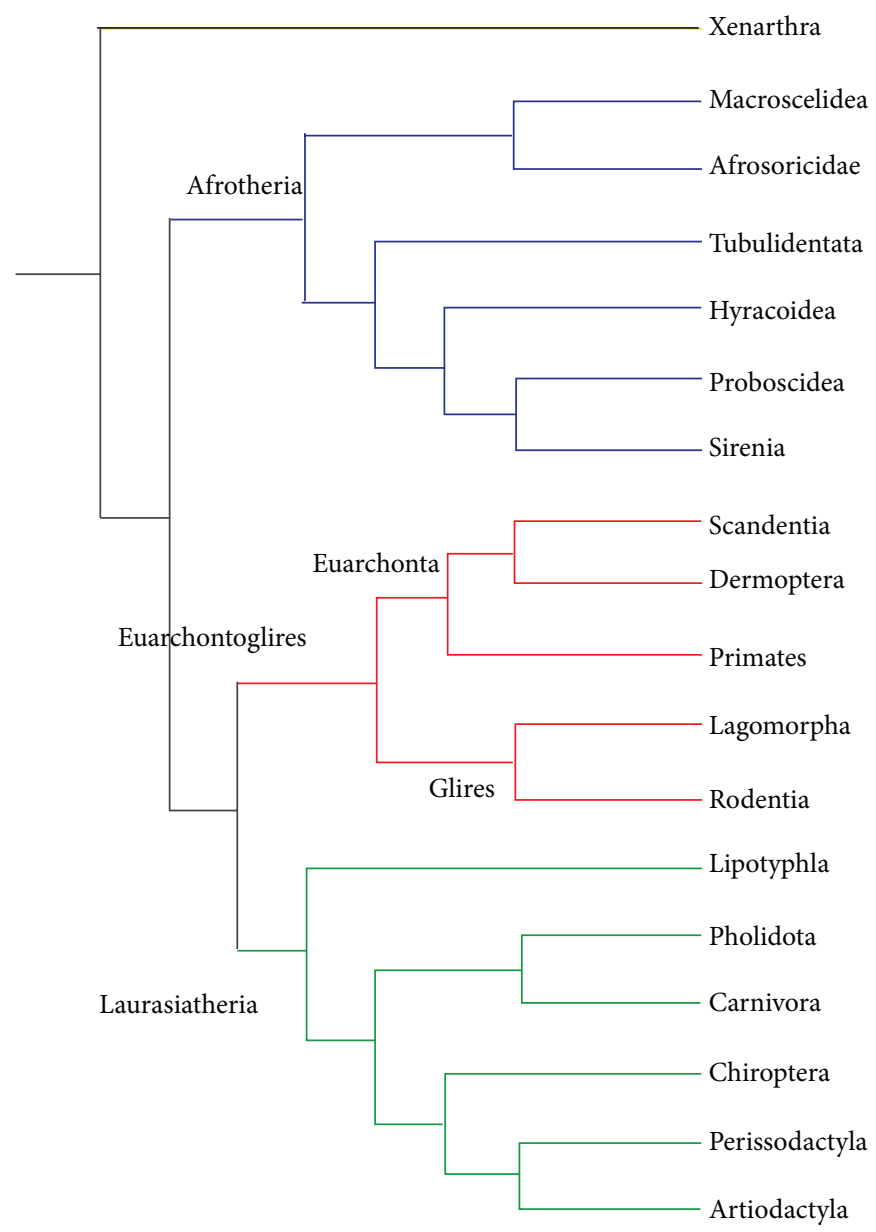

FIGURE 1: Relationships of the orders of crown Eutheria as revealed by molecular phylogenetics [76], derived and modified from [71]. The newly established higher-level clades are Xenarthra (in black), Afrotheria (in blue), Laurasiatheria (in green), and Euarchontoglires (in red). Here Xenarthra is regarded as most basal split of the group. Alternatives resulted in a sister group relationship of Afrotheria and Xenarthra or a basal position of Afrotheria.

by fossil data of whales with rudimentary hind limbs [86]. Second, the order Insectivora was not supported at all by molecular data (only weak support by morphology: [85]). Consequently, the golden moles and tenrecs are now placed as a new order Tenrecoidea (Afrosoricida) into Afrotheria [8789]. For the remaining insectivorous species (except elephant shrews that are now placed into Afrotheria and tree shrews that are close to primates) the new order Lipotyphla or Eulipotyphla has been proposed [89]. Another positive effect of the current molecular classification is that it resulted as stable when morphological or fossil data were included into analysis [89]. It is worth mentioning that in 2007 BinindaEmonds et al. published a supertree analysis covering the highest amount of molecular and morphological data derived from more than 4000 species that was in accordance with earlier work [90]. However, an essential short-coming of the new classification of Eutheria is that from scratch it suffered from problems with rooting the tree. Even most recent systematic approaches resulted in opposite conclusions about the basic nodes, favoring either Xenathra [76], Xenarthra, and
Afrotheria [91] or Afrotheria only [67] as the first offsplit of the group. Nevertheless, the new higher-level systematic is well accepted by the scientific community and served as basis to trace the evolutionary history of placentation in the above studies. It will also be used in this review. In relation to animal models, it is worth considering that rodents and lagomorphs are placed in Euarchontoglires, that is, close to primates including the human, which strengthens their usage as model species [71]. Even though xenarthrans share some important similarities with humans, they are far distant in evolutionary terms, whereas the ruminant models are in between, because they are placed in the superorder Laurasiatheria that shared a common ancestor with Euarchontoglires [71].

\section{Fetal Membranes}

Reproduction in metazoans requires as a minimum the production of germ cells, that is, egg cells and sperm. Typically, these products are released freely in the water and are not associated with further parental investment. 


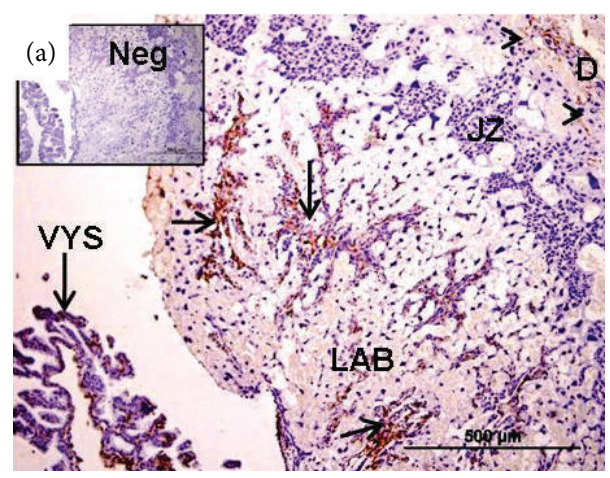

(a)

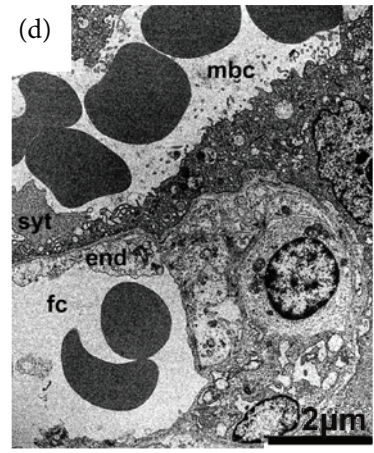

(d)

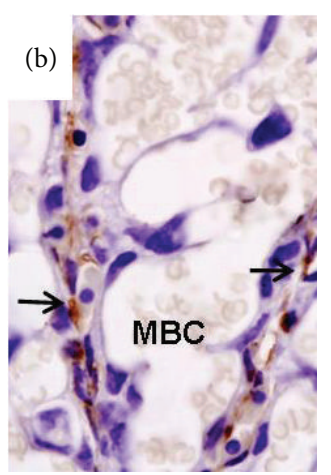

(b)

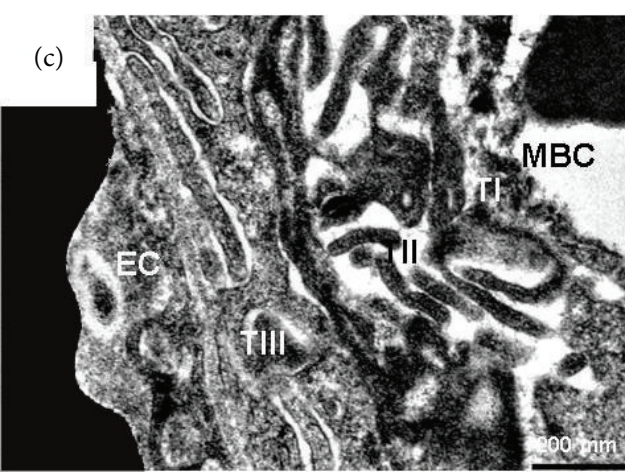

(c)

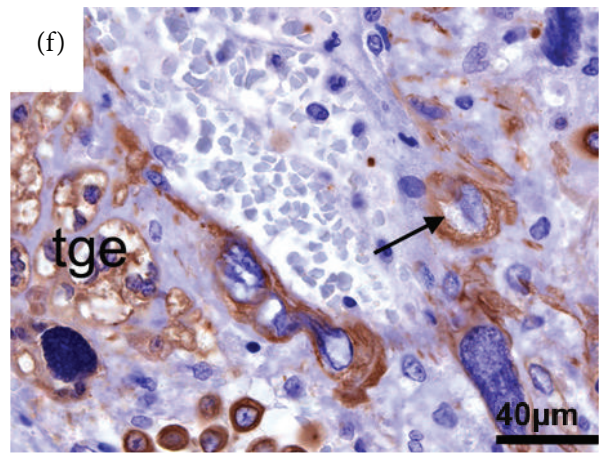

(f)

Figure 2: Placentation in Rodentia, derived from [32, 36, 223]. ((a), (b)) Necromys lasiurus (Muridae, Sigmodontinae = New World mice). The placenta consisted of the junctional zone and the labyrinth. The latter contains fetal vessels (arrows) and the trophoblast lining the maternal blood spaces. Immunostaining: vimentin. (c) Transmission electron microscopy (TEM) in Euryoryzomys sp. from the same group. The placental barrier is built by three layers of trophoblast above the endothelium of the fetal capillaries. (d) Galea spixii (Caviomorpha, Caviidae), TEM. The barrier between the maternal blood spaces and the fetal capillaries is thin and syncytial. Cellular trophoblast is present towards the inside. ((e), (f)) Trophoblast invasion in another caviid species, the capybara Hydrochaeris hydrochaeris, TEM, immunostaining for cytokeratin. Extravillous trophoblast giant cells and syncytial streamers have migrated towards the spiral arteries in the decidua and started to remodel their walls. The endothelium of the maternal blood system is discontinuous. $\mathrm{d}=\mathrm{decidua}, \mathrm{EC}=$ endothelium of fetal capillary, end $=$ endothelium of the maternal system, $\mathrm{fc}=$ fetal capillary, $\mathrm{Jz}=$ junctional zone, $\mathrm{LAB}=$ labyrinth, $\mathrm{MBS}=$ maternal blood space, syn $=$ syncytial trophoblast, TI-TIII $=$ trophoblast layers I to III, and tgc $=$ trophoblast giant cells.

Current hypotheses indicate that such a pattern with minimal reproductive effort is an ancestral condition of vertebrates [73]. Starting from that condition, several groups developed patterns of parental care. Most important in this regard are structural associations that allow the nourishment of the offspring, either after birth or hatching or during an intrauterine phase. In the latter case a placenta evolved, which is defined by its function in order to enable physiological exchange between the mother and offspring [9-11, 92]. Fetomaternal interactions of placenta systems have attracted much attention, primarily because they lead to the development of an organ involving tissues from two individuals belonging to two generations [7]. No parallels with similar intimate assemblages of coupling between the generations, that is, the offspring and maternal organism, via placental structures are known from other animal systems. Particularly in amniotes, viviparity and placentas evolved multiple times in parallel [93]. The evolution of additional extraembryonic membranes in amniotes, the amnion, allantoic, and chorion, working in concert with the vertebrate yolk sacs, seemed to be a suitable prerequisite to evolve a very high degree of reproductive plasticity including complex placental structures within many sauropsid lineages as well as in marsupial and placental mammals [7, 11, 74, 93, 94].

Placental or eutherian mammals are usually regarded to represent the vertebrate group with the most advanced placentation, including highly invasive types [3, 7, 9-11, 92]. The chorioallantoic placenta represents the main compartment of fetomaternal exchange in that group, but it may be supported by other structures such as the yolk sac $[10,11,13]$. Early in development, the conceptus differentiates into an inner cell mass, which produced both the embryo and the compartments of allantois, yolk sac, and amnion, as well as an outer sphere of cells, the trophoblast, leading to the developing chorion. The chorioallantoic placenta is formed from the trophoblast and allantois and is vascularised by the allantoic vessels running within the umbilical cord [10]. There is an astonishing variation in gross and fine structure 
of the placenta and its functional and developmental pattern in eutherian mammals $[9,10,23-25]$ and there are currently speculations about evolutionary forces leading to such diversity $[11,58,95]$. Some hypotheses considered conflicting interests of the mother and offspring that included the genetic level, because the offspring is characterised by both maternal and paternal genes [95]. The so-called "viviparity-driven conflict hypothesis" [96] states that viviparity creates an arena for genomic conflict after fertilization, resulting in rapid diversification of feto-maternal coevolution and antagonistic allocation of resources.

\section{Placental Characters}

Some important features of placentation in Eutheria or placental mammals will be introduced before going into detail to the supraordinal groups.

4.1. Placental Shape. The gross structure or shape of the chorioallantoic placenta varies from forming a disk as in the human, building a girdle that is regarded as zonary type, or, alternatively, having a diffusely extending chorionic sac within the uterus. In ruminants, the placenta is largely diffuse but possesses local areas of closely associated fetomaternal tissues, the placentomes, that comprise cotyledons and caruncles $[4,10]$.

4.2. Interdigitation. Internally, the degree of contact between maternal and fetal tissues at the area of exchange, known as interdigitation, varies [60]. As, for instance, in the human [97], the placenta may be villous. Branched chorionic villi are attached to the chorionic plate and have free-floating tipps. These villi are vascularised by fetal allantoic vessels and are in direct contact with the maternal blood in the intervillous spaces. Also, villous placentation occurs in Old World monkeys and great apes that has been convergently evolved in armadillos and anteaters $[45,71]$. In some taxa, neotropical primates for instance, the villi are connected by bridges of trophoblast (usually syncytial trophoblast), resulting in a trabecular condition $[52,71]$. A peculiar type in most placentas with a diffuse shape and some of the zonary type is that the villous trees interdigitate with corresponding areas in the uterine wall, forming, for instance, the placentomes of ruminants. Although this pattern was formerly regarded to be also a villous condition [10], there is no real structural and functional equivalence and, thus, the term should be avoided for this specialisation [71]. Finally, the most common type of internal structure, which is realized in laboratory rodent species, is a labyrinthine placenta, where the fetal capillaries run more or less in parallel to the maternal capillaries or blood channels $[10,26$, 98]. Often, labyrinthine placentas have an additional layer in between the labyrinth and the maternal decidua. This area, the so-called trophospongium (Hubrecht), spongy zone or junctional zone, consists of trophoblast that forms blood channels for the maternal blood but is not vascularized by fetal capillaries [26, 71]. Comparative studies revealed that interdigitation may be associated with reproductive tradeoffs.
In contrast to villous or trabecular placentas, species with labyrinthine interdigitation are characterized by two traits: the fetal growth rates seem to be higher as it means to increase the surface area for exchange, and gestation times are shorter. Such tradeoffs may reflect maternal-offspring conflicts over allocation of resources, with paternal genes favouring greater interdigitation and higher fetal growth, and maternal genes responsible for shorter gestation times [60].

4.3. Placental Barrier. Inside the main placenta, the following tissue layers can be included in the border between the fetal and maternal blood system, known as the interhaemal barrier [98]: the endothelium of the fetal capillary; the fetal connective tissue; the outer layer or layers of fetal trophoblast forming the chorionic epithelium; the uterine epithelium; the uterine endometrium or decidua as well as the endothelium of the maternal capillary [5]. In several lineages of placental mammals, maternal tissue layers are reduced, which was used to classify three principal placental types with differing degrees of invasiveness [5, 98]: the noninvasive, that is, epitheliochorial type with intact maternal tissue layers; the endotheliochorial type that has a medium degree of invasiveness with the reduction of maternal uterine epithelium and endometrium; and, finally, the highly invasive hemochorial placental type in which the fetus destroys the maternal arterial endothelium and controls the maternal blood flow. In hemochorial placentas attention was directed to the number of trophoblast layers, varying from one (human and guinea pig near term) to three (mouse, rat), resulting in hemomonochorial, -dichorial, and -trichorial conditions [4]. Since the placenta is important for gaseous exchange, it was assumed that the reduction of cell layers separating maternal from fetal blood affected the diffusion distance as one major factor determining oxygen transfer across the placenta [5, 99]. Particularly in hemochorial and endotheliochorial placentas, the invasive trophoblast has direct access to the maternal blood or blood vessels and the fetus has substantial control over the flow of nutrients. In hemochorial placentas, extravillous trophoblast (cellular and syncytial) migrates towards the maternal spiral arteries (endovascular trophoblast invasion) as well as into the decidua (interstitial trophoblast invasion) in order to establish trophoblast-lined channels for the maternal blood [12, 25, 53-56, 100-102]. However, the mode of trophoblast invasion varies even in closely related species like rat and mouse [71]. In contrast, the evolution of the noninvasive, epitheliochorial type may be triggered by benefits in maternal immunotolerance of the genetically different fetus that might be important in the evolution of a reproductive strategy with long gestation and precocial newborn, as what occurred in the Cetartiodactyla lineage $[5,103,104]$. However, often maternal and fetal capillaries became near to the surface, that is, the trophoblast and uterine epithelium, respectively, in order to optimize the diffusion distance $[5,103]$. A fascinating specialisation takes place in ruminants, called the synepitheliochorial placenta: partly, binucleate trophoblast cells fuse with maternal epithelial cells [71, 104-106]. 
4.4. Type of Trophoblast. The internal arrangement of the trophoblast varies either being cellular, called cytotrophoblast, or forming a fused area without cell borders, the syncytiotrophoblast, or even both. Some species like the mouse possess greatly enlarged cells within the trophoblast layer, called trophoblast giant cells. In bovines, fetal giant cells are mostly binucleate [105].

4.5. Specialised Areas. Besides the main region of the chorioallantoic placenta that mainly facilitates feto-maternal exchange processes, special structures such as paraplacentas, haemophagous organs, areolae, absorptive plaques, or trophoblastic fenestrae could be realized in various species $[4,10]$. Such specializations may facilitate the ingestion of glandular secretions, cell debris, and erythrocytes by the trophoblast, a pattern that is known as histiotrophic nutrition and that may occur in addition to hemotrophic nutrition $[4,7]$.

4.6. Yolk Sac Placentation. Finally, we will consider the yolk sac as an extraembryonic membrane occurring in all vertebrates $[10,13]$. In placental mammals, it may precede and support the chorioallantoic placenta during early gestation $[7,13]$ and it is regarded to be a primary source for haematopoiesis, erythropoiesis, and related processes [107, 108]. These latter functions prevailed in humans, where the yolk sac only indirectly participates in fetal nutrition as a temporary structure $[13,109]$. Developmentally, the yolk sac starts as an enclosure of the yolk mass within the yolk sac cavity by cells originating from the embryonic disc. The hypoblast (prospective endoderm) then develops an inner layer, forming the bilaminar omphalopleure. The developing mesoderm with its fetal vasculature migrates in between the hypoblast and the outer layer of the concepus, the epiblast that leads to the trophoblast of the chorion. Then a three layered or trilaminar omphalopleure is realized. Often, the mesoderm only reaches the superior portion of the yolk sac. Then, both the bilaminar and the trilaminar yolk sac are present at the same time $[10,13]$.

\section{Animal Models}

As recently stated, the human placenta is still not well understood [72]. Although proper placental development is crucial for a correct establishment and maintenance of pregnancy and also affects the lifelong health of both mother and offspring, the lack of knowledge about placental structure and function is particularly concerning. One modern approach to resolve this situation may be the so-called coordinated "Human Placenta Project" with the ultimate goal of understanding human placental structure, development, and function in real time [72]. However, experimental access to the human placenta is very restricted. Thus, animal models are an essential tool to better understand placental development, form, and function in comparison to the human [68]. Since none of the animal models currently used in that regard as well as any alternative species are entirely similar to the human, there is no ideal model. Researchers have to precisely formulate their questions, carefully choose the most adequate model species for particular purposes, and, most importantly, discuss their findings in relation to possibilities and limitations of the chosen model [71]. For instance, the mouse is an accepted and widely used model with easy access up to the molecular level, but it has important restrictions such as the highly complex and tri-layered trophoblast in the interhemal barrier and a mode of trophoblast invasion that is quite different and more shallow than in the human $[68,71]$. In a recent, comprehensive overview about the strengths and weaknesses of species in common use, we argued that besides structural and functional variation of the placenta especially differences in reproductive strategies have to be considered when choosing animal models for human placentation [71]. Since most laboratory rodents including the mouse have very short gestations that lead to the birth of poorly developed young, they may provide useful insights on placental development and function relevant to early human pregnancy, but not so much to model the requirements and events of a nine-month gestation with well-developed neonates [71]. Thus, other taxa with mainly precocial reproductive strategies should be considered in that regard. Thus, it is critically important not to focus on one model species. Comparative placentation is essential to enlarge and consolidate the pool of existing and potential models, especially for future applications that cannot well be resolved with the existing models [71].

\section{Eutheria}

All evolutionary reconstructions of the ancestral pattern of placental mammals or Eutheria suffer from the fact that the basal nodes or roots of the group are still not resolved, that is, that the first split could be either Xenarthra, Afrotheria, or both $[67,75-84,91,110]$. It was exemplarily shown for the hemochorial barrier that simple alterations in the rooting of a given tree changed the pattern of evolution [5]. In contrast, other characters analyzed under an evolutionary perspective seem to be not affected by alterations in rooting the tree $[4,5]$. However, having the shortcomings in mind, in the following the most important features that have been presumed to represent the ancestral condition or stem species pattern of placental mammals will be summarized. Several recent studies suggest that the type of the fetomaternal interface or barrier likely is hemochorial $[6,58]$, whereas own work originally supported an endotheliochorial condition [4]. It is worth noticing that these and other studies all state that the ancestral condition of placental mammals has the ability of an invasive trophoblast, but they disagree in the degree of placental invasiveness. In contrast, the noninvasive or epitheliochorial condition is regarded as a derived condition that evolved independently within Eutheria [5, 58]. Finally, the most comprehensive analysis on eutherian placental evolution is still the one derived from own work, representing altogether 21 characters of placentation and reproductive biology [4]. Results indicate that the chorioallantoic placenta is discoid in shape and labyrinthine in internal structure and that the fetal part of the contact zone is formed only of 
syncytiotrophoblast, at least in late or near term gestation. No placental specializations such as haemophagous regions or areolae appear in the ancestral condition of Eutheria. Both bilaminar and trilaminar omphalopleure are temporary; thus a functional choriovitelline placenta is absent at term. Then, the yolk sac is either reduced or free without contact to the chorion. The pregnancy is established in a bicornuate uterus and the newborn are altricial [4].

\section{Xenarthra}

Xenarthra belong to the ancient fauna of South America. They are known from the fossil record from the mid Paleocene onward, but their origin may be older [52, 76, 90, 111-113]. There are three morphologically distinct subgroups that contain relatively few species. These are Cingulata, that is, the armadillos, or Dasypodidae on the one hand side as well as Pilosa that includes both the sloths (Bradypodidae and Megalonychidae) and the anteaters (Vermilingua: Myrmecophagidae and Cyclopedidae) on the other hand $[75,114]$. Besides their systematic position, armadillos and anteaters are more similar to each other in sharing a villous and hemochorial type of placentation [44, 45, 115-117], in contrast to the sloths that are characterised by lobulated, labyrinthine, and endotheliochorial placentas $[24,118]$. The similarity between the two former taxa suggests that their condition occurred in the ancestral condition or last common ancestor of Xenarthra, whereas the endotheliochorial placenta of sloths likely is a derived state that evolved after the dichotomy of sloths and anteaters [52]. From the standpoint of animal models for human placentation, xenarthrans are usually not much taken into consideration $[68,71]$. However, besides higher primates including the human, armadillos and anteaters are the only placental mammals that evolved a true villous condition of the placenta. Even if they are not an easy choice for laboratory approaches, or if they are endangered, it is worth learning more about their peculiar mode of placental establishment, in comparison to what is known about the human placenta.

Anteaters and armadillos share important similarities, likely representing ancestral conditions of Xenarthra. Such similarities are placental establishment at the fundic region of the uterus, the extended to disc-like placental shape, the complexly intermingled trabecular and villous areas (Figure 3(a)), the dominance of cellular trophoblast in the trabeculae (Figures 3(a) and 3(b)), the syncytiotrophoblastic and thin surface of the villi (Figures 3(b) and 3(c)), the location of fetal capillaries partly near the surface in association with hypertrophied mesenchymal cells (Figure 3(c)), and the presence of proliferating trophoblast cells at the tips of the villi (Figure 3(b)) [45]. Most of these features exhibit parallels to humans [119]. In humans the syncytiotrophoblast is formed from proliferative cytotrophoblast cells and we have suggested that the cytotrophoblast cells in xenarthran species have a similar function [52]. However, the villous pattern in anteaters (giant anteater Myrmecophaga tridactyla, lesser anteater Tamandua tetradactyla, and two-toed anteater
Cyclopes didactyla) is much simpler in terms of developmental differentiation and more similar to humans than the condition in armadillos. In particular, recent applications of immunohistochemistry and transmission electron microscopy [45] supported previous hypotheses on standard histology [119-122] in the fact that the feto-maternal interface is fully hemochorial, that is, without remnants of the maternal vessel endothelium along the trabeculae (Figure 3(c)). Thus, even in early gestation the trophoblast is fully invasive throughout the placenta [45]. Consequently, only the villous types of anteaters show sufficient parallels to human placentation. In contrast, in armadillos (placenta studied in Dasypus novemcinctus and some other species: $[23,44,115-117,123])$ the developing villi enter preexisting maternal blood sinuses and enlarge them initially leaving the endothelium largely intact. The sinuses become confluent to form an intervillous space, supplied by derivatives of the uterine spiral arteries. Thus, the fetal tissues develop inside the sinuses, representing an endotheliochorial state at the base of the villi as well and an invasive, true hemochorial condition at the villi tips $[23,44,117]$. This unique mixture of endotheliochorial and hemochorial areas, which was recently confirmed by the application of immunohistochemistry [44], likely resulted as an evolutionary transformation on the armadillo stem lineage $[45,52]$. In addition, in anteaters the depth of trophoblast invasion is shallow and mainly restricted to the surface of the decidua $[45,119,121,122]$, whereas it is reaching deeply into the myometrium in armadillos $[44,115-$ $117,123]$, likewise regarded as an evolutionary transformation on the stem lineage of the latter $[45,52]$. Sloth placentation is different to these conditions. The distinctly lobulated and labyrinthine placenta has an endotheliochorial barrier with a single syncytiotrophoblast layer and enlarged endothelial cells of maternal capillaries [24, 52, 118]. Spaces occur within the trphoblast, which opens towards the maternal endothelium [52]. These features are far different to the condition in the human for sloths to be regarded as a suitable animal model.

\section{Afrotheria}

Afrotheria represents a supraordinal clade of placental mammals with all extent members living in Africa and Madagascar or having an African origin at least. This novel clade was proposed by molecular systematics from the late 1990s onward [77]. Previously, closer interrelationships were suggested only among subsets of endemic African mammals, that is, the Paenungulata that comprises elephants (Loxodonta), sea cows (Sirenia), and the Hyracoidea or hyraxes [85, 124]. Paenungulata still form a valid systematic cluster within Afrotheria, usually with hyraxes and sea cows together as sister group to elephants $[125,126]$. The second main subgroup of Afrotheria includes the tenrecs and golden moles as Tenrecoidea or Afrosoricidae in a sister group conrelationship to elephant shrews or sengis, the Macroscelidae, and the two of them sister to the aardvark as the one and only extant representative of Tubulidentata $[76,126]$. The new, molecular higher-level systematics has stimulated morphological approaches and 




(a)



(b)

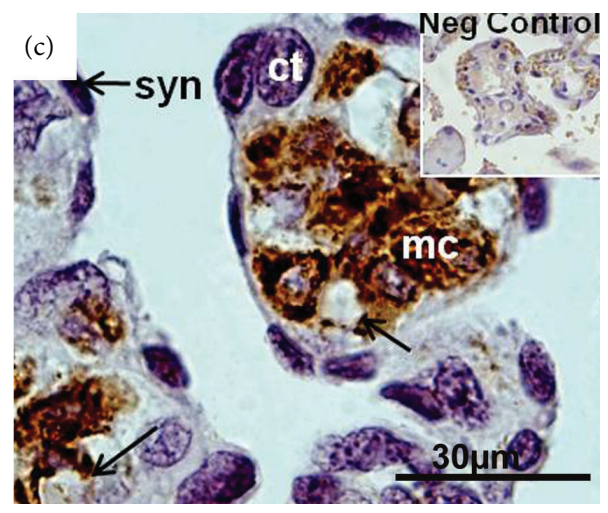

(c)

Figure 3: Placentation in a xenarthran species, the giant anteater Myrmecophaga tridactyla, as derived from [45]. (a) The placenta consisted of villous and trabecula areas that both reached the decidua. (b) Clusters of proliferative trophoblast cells (white arrows) are frequent in the trabeculae and the tips of the villi that included fetal capillaries (black arrows). Immunostaining for PCNA. (c) The villi surface is syncytial without remnants of the maternal capillary endothelium, revealed by negative response to immunostaining for vimentin, built by syncytial and cellular trophoblast. Inside is hypertrophied mesenchyme. $\mathrm{ct}=$ cellular trophoblast, $\mathrm{dec}=$ decidua, INS $=$ intervillous space, $\mathrm{mc}=\mathrm{maternal}$ capillary, Syn = syncytiotrophoblast, trab = trabeculae, and villi $=$ villous area of the placenta.

there is now also structural support for Afrotheria, including data derived from the fetal membranes, the skeleton and dentition [4, 126-128]. Although the six subtaxa of Afrotheria are morphologically diverse, they contain relatively few recent species, that is, 2 species of elephants (Loxodonta africana, Elephas maximus), 4 sea cow species, 5 hyrax species, 1 aardvark, 18 species of Macrocelidae, and 55 of Tenrecoidea [75]. Afrotheria are known from the fossil record since the Paleocene [129], but their origin may be older. Some authors suggest that it reached more than 100 million years ago into mid Cretaceous times, when the African continent separated from other major land masses [82]. None of the members of Afrotheria have been considered as animal model for placentation in the human [71], especially because placentation is far too different or the general life style is very specialized in being either a small-sized insectivorous animal, a strictly plant-eating giant like the elephant, or an aquatic mammal like the manatees or sea cows. Moreover, many members of Afrotheria have a high risk of extinction [130].

Data so far suggest that the ancestral condition of placentation in Afrotheria may be realized mainly by the ancestral character conditions of placental mammals (see above), except the following: the large, four-chambered allantoic sac most likely represents a new synapomorphy for the superorder $[4,57]$. Although many taxa of Afrotheria have haemophagous regions or areolae, such specialized areas seemed to be not characteristic for Afrotheria in general, but they seem to have evolved independently in elephants, aardvarks, and within Tenrecoidea [4]. Finally, within Afrotheria, only most tenrecs, the elephant shrews and the hyraxes possess hemochorial placentation, whereas the other taxa are endotheliochorial. Paenungulata have two derived character conditions that the fetal part of the barrier consists of cellular trophoblast and implantation takes place centrally rather than antimesometrially [4].

\section{Laurasiatheria}

Established by molecular phylogeny, Laurasiatheria represents the most diverse and very species-rich supraordinal clade of placental mammals that has evolved on the northern supercontinent of Laurasia after it split from the main land mass of the supercontinent Gondwanaland [79, 82, 131]. Together with Euarchontoglires, Laurasiatheria forms the high-level clade Boreoeutheria [76, 82]. True laurasiatherian taxa are known from the fossil record from the early Eocene on, but likewise to the other supraordinal clade an origin that harks back to Paleocene or Cretaceous times seems to be likely $[83,84,112]$. Then, a very rapid evolutionary radiation was assumed [132]. Laurasiatheria contain Cetartiodactyla (even-toed ungulates or hoofed mammals, known as Artiodactyla, with camels, pigs, ruminants (giraffes, deer, antelopes, cattle, sheep, goats), and hippopotamus as well as whales and dolphins, formerly known as Cetacea) and Perissodactlya (odd-toed ungulates, such as horses, tapirs, and rhinoceroses). Together, they are sister to a clade comprising Carnivora (cats, dogs, bears, seals) and Pholidota (pangolins), regarded as Feraeungulata $[76,80,124]$. The next split was the bats (Chiroptera) and the remaining insectivores (hedgehogs, moles, shrews, and solenodons) that are summarized within the new order Eulipotyphla $[133,134]$. Although placentation in the members of Laurasiatheria is quite different from human beings, large domestic ruminants such as the sheep or the bovine have been used as animal models and, recently, there are some studies on the dog model [71].

In regard to placental evolution, Laurasiatheria seems to have conserved the ancestral condition of placental mammals [4]. Evolutionary transformations occurred, for instance, on the stem lineage towards Eulipotyphla and within this clade, including features such as permanent establishment of the bilaminar and trilaminar omphalopleure that lead to a permanent and inverted yolk sac placenta [4]. In 
addition, a remarkabe plasticity in regard to the nature of hemochorial barrier (hemochorial versus endotheliochorial: $[2-6,58])$ occurred; however, because of the problems in rooting the Eutherian tree the exact evolutionary steps are not fully resolved. Chiroptera, comprising megabats and four clades of microbats, evolved a high variability in regard to reproduction and placentation $[4,21,41-43,135,136]$, for example, the occurrence of a gland-like yolk sac with complete obliteration of the yolk sac lumen on the stem lineage towards the megabats. Among the microbats, the most remarkable evolutionary transformations are the interstitial mode of implantation and the amnion formation by cavitation in Noctilionoidea, the hemophagous region in Emballonuroidea, and establishment of the placenta near the uterotubal junction in Vespertilionoidea [42]. Feraeungulata shares two evolutionary transformations with the bats, namely, the presence of cytotrophoblast in the interhemal membrane of the definitive placenta (Figure 4(a)) as well as the mesometrial attachment of the blastocyst, followed by the evolution of a diffuse, epitheliochorial placenta with areolae towards the stem lineage of Feraeungulata [4]. The latter is preserved within the group, characterizing, for instance, the ancestral pattern of the Cetartiodactyla (Figure 4(b)) [104]. Then, evolutionary transformations occurred within Ruminantia, resulting in polycotyledonary placentas with 50-150 placentomes and, secondarily, in oligocotyledonary ones with only few placentomes [104]. Such placentomes consist of the cotyledons as the fetal portions and the maternal caruncles, which become closely associated with each other (Figure 4(b)). The evolution of cotyledons resulted in significant increase in the placental exchange area. Further transformations within ruminants lead to highly branched fetomaternal interdigitation inside the placentomes $[60,104]$. Moreover, bi- and multinucleated giant cells evolved independently within ruminants (Figure 4(b)) and in camelids $[104,105]$, which may contribute to compensate the assumed limited endocrine influence of the fetus on the maternal organism in an epitheliochorial type of placentation, in which fetal tissues are generally distant from the maternal blood system $[5,25]$. The binucleate giant cells of ruminants fuse with maternal epithelial cells to release mediator substances [104]. This hypothesis is supported by a current study on bovine placentation, using a model of transgenic enhanced Green Fluorescent Protein-expressing embryos produced by nuclear transfer. Data show a delivery of fetal contents into the maternal system (microchimerism), indicating that the bovine synepitheliochorial placenta displays intimate fetal-maternal interactions similar to other placental types [137]. Finally, transformations within Ferungulata have been evolved within Carnivora, for example, secondary evolution of a zonary, labyrinthine, endotheliochorial placenta (Figure 4(a)) as well as the antimesometrial attachment of the blastocyst [4].

Much of our current knowledge of placental physiology including transfer functions and capacity as well as placentalfetal and maternal interactions has been gleaned from investigations using large animal models belonging to Artiodactyla, most commonly, the sheep $[71,138,139]$. The sheep has a polycotyledonary placenta with up to 100 cotyledons that vary in number and size between individuals $[140,141]$. In particular, the sheep was used to develop techniques for catheterization of the uterine and umbilical vessels. Such techniques allow repeated sampling from nonanesthetized animals free of surgical stress in order to obtain data on fetomaternal exchange processes, placental gas exchange, and fetal oxygen supply, under in vivo conditions and experimental manipulations $[68,71,138,139,142,143]$. The oxygen consumption of the placenta as a highly metabolically active organ is between half and $80 \%$ of the total oxygen uptake by the gravid uterus, mainly used for oxidative phosphorylation of glucose [141143]. Indeed, about $80 \%$ of the uteroplacental glucose uptake is consumed by the placenta and not transferred to the fetus [144]. Acute reduction in the uterine oxygen supply usually affects the fetus, whereas placental oxygen uptake remains constant [139]. Moreover, the sheep is used as an experimental model of fetal growth restriction, comparable to early-onset severe fetal growth restriction (FGR) in humans. Inadequate oxygen supply is associated with reduced placental oxygen consumption [138]. Conditions of hypoxia lead to anaerobic glycolysis and apoptosis in definitive placentas and reduced branching patterns in earlier stages [139, 145]. Although by no means a perfect model for human pregnancy, the sheep has been proven as a useful choice for experimental studies in regard to metabolic function, gas exchange, and nutrient transport of the placenta. The long gestation and the advanced developmental condition of the newborn are important similarities to reproduction in humans $[71,139]$. However, its epitheliochorial type of placentation limits its value for placental research [71].

In addition, animal models are essential to more fully understand the risks of assisted reproductive techniques in comparison to the human. In humans, such methods may provide promising results for individuals with problems inhibiting normal reproduction but are not well understood in regard to health consequences of the mother and the offspring [146]. Applied methods include, for instance, artificial insemination, in vitro fertilisation, and, in regard to animal species, cloning by somatic cell nuclear transfer. However, the pregnancy outcome suffers from limitations caused by the artificial treatments and in vitro culture of the germ cells and associated, altered patterns of gene expression [147-150]. This affects the health status of the newborn but also influences later periods of live. The following alterations may occur: obstetrical complications, preeclampsia, preterm birth, low birth weight, imprinting phenotypes, infertility, or the onset of cancer [149-152]. Recently, several studies deal with the effects of reproductive techniques in domestic cattle, because assisted reproduction is commonly applied and the bovine has a long gestation period with well-developed newborn $[153,154]$. In contrast to the less manipulative methods, nuclear transfer is still associated with an extremely high rate of prenatal mortality with less than $5 \%$ of successful pregnancies until term and also a high postnatal mortality $[154,155]$. Recent results showed that in the bovine the application of all these methods is followed by severe alterations in both the placenta and the yolk sac as well as in the developing conceptus. In particular, the early differentiation of the 




(a)



(b)

Figure 4: Placentation in Laurasiatheria. (a) Chorioallantoic placenta in a carnivore, the coati Nasua nasua, with nests of cytotrophoblast in the barrier and a maternal vessel with intact endothelium, representing an endotheliochorial type of placentation. Derived from [260]. (b) The synepitheliochorial bovine placenta near term with binucleate giant cells and fetal capillaries between the trophoblast cells. Derived from [104], modified. $\mathrm{bgc}=$ binucleate giant cell, $\mathrm{ct}=$ cellular trophoblast, endo $=$ endothelium, $\mathrm{fc}=$ fetal capillary, $\mathrm{mv}=$ maternal vessel, trp $=$ trophoblast, and ue $=$ uterine epithelium.

cardiovascular system seems to be very sensitive in regard to developmental problems in early gestation, suggesting an altered expression of associated genes [156-161]. Vascular endothelial growth factor (VEGF) and basic fibroblast growth factor (bFGF) genes are regarded as major stimulating factors for such processes and have been proven to be altered at least in term pregnancies of bovines from nuclear transfer [162, 163]. Currently, a more comprehensive analysis in bovines derived from various techniques with special reference to the more critical early phases of gestation is under way; first results suggest that the expression of these genes indeed is disturbed (personal observation). Some authors suggest that such alterations lead to further developmental problems such as the large offspring syndrome or gigantism as well as multiple organ defects that are occurring especially in bovines from nuclear transfer $[156,161]$. In sum, the bovine is an important model for health problems caused by assisted reproductive techniques, because the high rate of pregnancy loss is in large part due to failures of placentation [71].

Finally, there are recent studies on preeclampsia in the dog model $[164,165]$. In humans, this disease results from shallow trophoblast invasion into the endometrium and myometrium, followed life-threatening conditions for both the mother and the fetus. Since the dog has shallow trophoblast invasion throughout gestation, it may improve the understanding of the underlying reasons and exact mechanisms for pre-eclampsia [164]. Data show that the shallow trophoblast invasion in the endotheliochorial placentation of dogs is mainly regulated by matrix metalloproteinases, similar to what is known from humans [165]. Thus, the dog may be worth to consider as a model for disorders of shallow trophoblast invasion in humans [165].

\section{Euarchontoglires}

Euarchontoglires is the third supraordinal clade of placental mammals as revealed by molecular phylogeny. It is sister to the Laurasiatheria (within the high-level clade Boreoeutheria), from which it has separated during Cretaceous times and evolved on the Northern continents, in particular on that part of the Laurasian land mass that led to the European continent [76, 166-168]. Crown Euarchontoglires include Glires, that is, Rodentia (rodents) and Lagomorpha (hares, rabbits, pikas), as well as Euarchonta, consisting of Scandentia (tree shrews), Primates (lemurs, monkeys, and apes including the human), and the flying lemurs belonging to the order Dermoptera [79, $81,82,90]$. Former uncertainties, that is, the association of the lagomorphs close to primates in the first molecular study and the placement of the tree shrews relative to primates or Glires, have been resolved [169-171]. Even before Glires for Rodentia and Lagomorpha was supported by molecular phylogeny $[73,78,79,90]$, there was evidence for this clade from traditional morphological systematics and the fossil record: Glires are characterized by the evolution of gnawing and the associated modifications of the rostral snout region, that is, the transformation of the skin (rhinarium) from a manipulation organ into an internally directed area called the narial pad, the differentiation of a flexible rostral nasal cartilage as well as the gnawing incisors, the formation of inflexa pellita from the skin of the cheek to protect the inner mouth region from the gnawing process, and skull arrangements in regard to the incisors [1, 85, 169, 170, 172-177]. In addition, characters of the fetal membranes and placentation have been used as an independent support for Glires $[1,172]$. Finally, the linkage of the primates to tree shrews and culugos within the systematic clade Euarchonta harks back to the traditional Archonta-concept of the traditional system, but under exclusion of Chiroptera $[79,81,84,170]$, which are therefore less attractive as potential animal models [71].

In regard to placental evolution, Euarchontoglires seems to be conservative in maintaining the ancestral conditions of placental mammals [2-6]. Evolutionary transformations occurred on the stem lineage of Glires, including the establishment of a labyrinthine, hemochorial placenta opposite to the attachment of the blastocyst at the mesometrial side of the uterus, divided into the labyrinth that is capillarized by embryonic vessels and the spongy or junctional zone without fetal vasculature and consisting of an interconnected network 
of trophoblastic channels (Figures 2(a) and 2(b)) and an incompletely inverted yolk sac that may maintain transfer processes in addition to the main placenta $[4,6,85,172]$. For some taxa, however, murids for example, it was shown that the spongy zone largely disappears in late gestation $[9,10]$. Rodentia are characterized by the following evolutionary transformations: the complete absence of the trilaminar omphalopleura or yolk sac placenta and the reduction of the allantoic vesicle $[4,13]$. They possess by far the highest species diversity among mammalian orders [75] and have been regarded to be highly significant with regard to ecosystem processes and human social development. Moreover, members of Rodentia commonly have been used as models for medical research including applied placental studies. The close relationship to the human from a phylogenetic standpoint and the fact that many species are easy to maintain and breed under laboratory conditions support their appropriateness as animal models [71]. Within Rodentia, further transformations are frequent and concern murine rodents, which have secondary interstitial or invasive implantation, a complex, tri-layered structure of the placental barrier with both cyto- and syncytiotrophoblast (Figure 2(c)), the fenestrated endothelium of the fetal capillaries, and reduction to one umbilical artery $[4,26,172]$. Also, caviomorphs and relatives evolved a complex of derived conditions of fetal membrane and placental characters [26, 171, 172]. For Lagomorpha, the two-layered trophoblast structure in the placental barrier seems to be a derived character condition [4]. Finally, in the other main group, the Euarchonta, the tree shrew (Tupaia) is characterized by the following transformations: lateral implantation, resulting in a double discoid placenta, and the retainment of the trilaminar omphalopleure or yolk sac placenta until term $[4,178]$. If the endotheliochorial placental barrier that distinguishes Tupaia from other Euarchonta $[4,6,179]$ is a derived or basal character condition is difficult to decide [5]. On the stem lineage of primates villous placentation and a precocial reproductive strategy evolved $[4,6,58]$. The bush baby (Galago) and probably lower primates in general evolved areolae as specialized uptake areas inside the main placenta and a barrier consisting of cellular trophoblast in advanced gestation and near term [4]. Convergent to Afrotheria, Galago evolved a two-parted allantoic vesicle [4]. Further steps of evolution occurred toward the human, including primary interstitial implantation, the absence of an allantoic vesicle, the restriction of the bilaminar omphalopleura to the blastocyst stage, and the complete absence of the trilaminar omphalopleure [4].

Among Euarchontoglires members of the Glires contribute essentially as animal models, especially the mouse and rat, the guinea pig, and the rabbit, but important similarities to the human also occur among subgroups of Euarchonta [5, 71]. However, our functional and experimental understanding of placentation in comparison to the human is largely due to the mouse model (Mus musculus) as by far the best investigated species in that regard. Even though it is not the aim of this contribution to repeat the astonishing amount of data on mouse placentation, so far special reference has been given to the early establishment of the placenta, the associated genes and cell lineages, relevant knock out models, and in regard to common pregnancy disorders such as fetal miscarriage, preeclampsia, or intrauterine growth restriction (e.g., [18, 70, 71, 180-194]). Also, several studies deal with placental aspects in the laboratory rat Rattus norvegicus (e.g., [70, 71, 195-206]). However, besides these truly important approaches there are also severe differences in comparison to the human placenta that are essential to understand as restrictions in using the mouse or rat as animal model. First, the murine rodents have a very complex, hemotrichorial placental barrier (Figure 2(c)). The outer layer is facing the lumen of the maternal blood channels and formed by a discontinuous layer of cellular trophoblast that harks back to fetal giant cell lineages. Towards the inside, two layers of syncytial trophoblast are present [181, 207]. It can be assumed that differences from the mainly syncytial barrier of the definitive human placenta affect fetomaternal exchange processes [71]. Moreover, the mouse possesses a shallow, primarily interstitial mode of trophoblast invasion that is restricted to the mesometrial decidua, leaving the maternal arteries inside the decidua intact with their endothelial lining, and established mainly by giant cell lineages $[188,199]$. In contrast, in the human an extensive invasion of trophoblast into the uterine arteries occurs that is established by several lineages of extravillous trophoblast derived from proliferating trophoblast cells at the base of the cell colums [120]. In addition, maternally derived uterine natural killer cells (uNK cells) are involved in the the invasion processes and the remodeling of the spiral arteries. The uNK cells have become frequent in the endometrium during gestation in both the mouse and the human but vary in regard to functional aspects and surface receptors [12, 208-210]. Even though in the rat trophoblast invasion goes deeper and uses both interstitial and endovascular routes well into the metrial gland region [199], it reacts differently in regard to pregnancy disorders [71]. We argued that not only the structural and functional differences from the human placenta, but also differences in reproductive strategy provide the most essential drawback for using murine rodents as animal models for human placentation. They have brief gestations resulting in the birth of poorly developed young, which may provide insights on the placental development and function relevant to early human pregnancy, but not to model events and requirements of a nine-month gestation [71]. In sum, we have argued that the mouse is not an adequate model for the later events of human pregnancy and cannot help much to better understand pregnancy disorders such as fetal growth restriction and preeclampsia [71].

Particularly in the last decade, the Caviomorpha or caviomorph rodents, that is, the guinea pig Cavia porcellus and its relatives, came more and more on focus in regard to animal models for human placentation $[68,71]$. These rodents reached the South American continent during a phase of complete isolation from the other continental plates presumably from an African origin via drifting or island-hopping over the South Atlantic Ocean [171, 211, 212] and underwent an impressive and explosive radiation from late Eocene or early Oligocene times onwards [171, 213-215]. Together with Old World taxa, that is, the porcupines, cane and rock rats, and blind moles, they form the group Hystricognathi 
[216], well supported by molecular and morphological data [75, 171-175, 211, 217-221]. Hystricognaths are characterized by evolutionary transformations in the rostral head region such as the complete loss of tactile ability in the nasal skin (rhinarium) and a mobile rostral nasal cartilage that are associated with a switch from omnivorous to herbivorous and fiber-rich nutrition [169-182, 220, 221]. Also a very stable pattern of fetal membrane and placental characters has evolved on the stem lineage of hystricognath rodents [26$30,171,172]$ that is relatively similar to the placental fine structure in the human $[27,28,71,101]$. Inside the placenta, proliferating trophoblast cells are situated on bands of fetal mesenchyme, lined by syncytial trophoblast facing towards the maternal blood spaces [27, 28, 34, 35, 222, 223]. In near term pregnancy, the exchange area consists of a single, very thin layer of syncytiotrophoblast (Figure 2(d)) as does the mature human placenta $[26,171]$. Implantation is invasive or superficial [172]. The guinea pig and other hystricognaths have a unique structure called a subplacenta from which extravillous trophoblast migrates to invade deeply inside the decidua (Figures 2(e) and 2(f)) and transform the maternal arteries $[10,26,29,34,35,171,172,223]$, in parallel to the structure and function of the human cell columns [120]. Other derived character conditions of hystricognaths are the ring-shaped placenta with radial flow of maternal blood in order to increase the capacity for passive diffusion [26]. The visceral yolk sac is completely inverted, facilitates substance exchange with the placenta, and has a fibrovascular capillary ring system $[13,26,30,33,40,171,172]$. Finally, hystricognaths have relatively long gestational periods, associated with precocial newborn [71, 171, 221]. Consequently, the caviomorphs provide reliable similarities especially in regard to the events late in human pregnancy and are regarded as promising animal model for studies including trophoblast invasion, placental physiology such as growth and exchange processes, and fetal growth restriction or pregnancy toxemia [71]. However, there was criticim about using the guinea pig and other small-sized caviomorphs for such purposes. In particular, it was questioned, if it is possible to compare such smallsized animals with the condition in the human. However, principle processes of placentation in caviomorph rodents are not dependent on body size, as was shown by studies on the capybara (Hydrochaeris hydrochaeris). The capybara represents the largest species of recent Caviomorpha, which approximates human dimensions with an adult body mass of around $50 \mathrm{~kg}[223,224]$. Likewise, specialized reproductive traits in other caviomorphs such as polyovulation in the plains viscacha (Lagostomus maximus) do not affect the set of placental features typical for the caviomorphs [35], supporting indeed their appropriateness as animal models.

Among the second group of Glires, the Lagomorpha, the rabbit Oryctolagus cuniculus has been traditionally used as an animal model, particularly in regard to reproductive endocrinology and physiology including the exploration of the countercurrent exchange mechanism of maternal and fetal blood inside the labyrinthine placenta $[10,68,225]$. After decades of neglect, there are recent attempts to reintroduce it as a model species [71, 226]. Indeed, several studies deal with aspects of toxicology and health purposes, nutritional consequences in regard to intrauterine growth restriction, and characteristics of receptors and genes associated with placentation in the rabbit $[216,226-230]$. The main concern against the rabbit is that it has a hemodichorial type of barrier even at term, built by a syncytial layer lining the maternal blood channel and cytotrophoblast layer beneath as well as a short gestation and poorly developed newborn $[9,10,172,225,231]$. Besides the fact that the rabbit may serve as an interesting model, the latter drawback especially may restrict its appropriateness to just the early events of human placentation [71].

Within Euarchonta nonhuman primates have to be considered as potential animal models for human placentation $[68,71]$. Recently, members of the order Primates are distributed all over the world [75], starting from the occurrence of close relatives in the fossil record in the Paleocene [76, 232]. Primates have been divided into Strepsirhini or wetnosed primates that consist of the lemurs and lorises, and Haplorhini, that is, dry-nosed primates that include tarsiers and simians or Anthropoidea. The latter group includes Platyrrhini, that is, the New World or "flat-nosed" monkeys such as capuchins or howlers, as well as the catarrhine or narrow-nosed monkeys, which comprises the Old World monkeys such as baboons or macaques, the gibbons, and the Great Apes including the human [233-235]. Lower primates are quite different to the human, especially in the fact that most groups have noninvasive, epitheliochorial placentation [4, 236-239]. New World or Neotropical primates are more attractive models but also differ in key aspects [71]. They have placentas with trabecular structure, where tips of the villous trees form bridges of trophoblast, and intertrabecular spaces are supplied by intraplacental capillaries with thick basement membranes. The syncytial trophoblast is directly attached to the decidua without clear signs of trophoblast invasion [52, 236-240]. In contrast, the Old World monkeys are more similar to the human condition [10, 71, 237]. Extravillous trophoblast and spiral artery remodeling also occur in baboons and rhesus monkeys, but with two differences. There is relatively shallow trophoblast invasion that rarely reaches the level of the myometrium. It is restricted to an endovascular route along the spiral arteries in early stages only; in contrast, there is no invasion by the interstitial route via the decidua [241-247]. The differences matter a lot, because shallow trophoblast invasion as well as limited spiral artery remodeling is normal in monkey, whereas in human pregnancy it is associated with both preeclampsia and fetal growth restriction [71]. Finally, in the gibbon and the great apes, interstitial implantation complemented the endovascular route and the trophoblast invasion is not as shallow as in the Old World monkeys $[68,237,248]$. However, extravillous trophoblast invasion towards the inner third of the myometrium and the associated remodeling of deep parts of the spiral artery is known only for the human, chimpanzee, and gorilla $[53-56,65,71,237,249,250]$. Data show that the great apes most likely resemble the human condition in the fact that the villous trees are anchored to the basal plate by trophoblast columns. Starting from these cell column trophoblast cells migrate deeply into the decidua and 
towards the spiral arteries $[10,53-56,65,71,102,251,252]$. Accordingly, recent evidence from both the chimpanzee and the gorilla has raised doubts that preeclampsia is a uniquely human disease [53]. Besides all these astonishing similarities in placental form and function including the routes and depth of trophoblast invasion in comparison to the human, ethical considerations clearly restricted the use of great ape species for experimental approaches [71]. Thus, if primate models are necessary, members of Old World monkeys such as rhesus macaques or baboons may represent appropriate alternatives. It has been proven for placental circulation, gas exchange, endocrinology and immunological as well as to model in parts aspects of pregnancy hypertension or other defects [253-259]. However, their shallow trophoblast invasion limited the usability as model species for preeclampsia [71]. Moreover, ethical and practical aspects, such as the long generation periods and the high costs of maintenance in laboratory settings, likewise need to be considered [71].

\section{Conclusions}

The placental system and the fetal membranes evolved an astonishing complexity and diversity following the radiation of placental mammals. This plasticity may have been driven by evolutionary intraspecies tensions between the mother and the fetus and the involved genes. Likely, such tensions resulted in a field of opposing processes between the parent and offspring (often called "battlefield" or "arms race") that led to a very high degree of species-specific variation $[15$, $17,95]$. These selective pressures and evolutionary forces are regarded to be responsible for many pregnancy diseases. In consequence, a better understanding of the basic processes in various species will provide key insights into diseases of pregnancy in the human [17]. This is especially important, because relevant features of human placentation are present only in the great apes such as the chimpanzee and the gorilla, but ethical reasons strongly prohibited their usability for experimental approaches. Besides there is not one single species that is entirely similar and that could serve as an ideal model in comparison to human placentation $[71,120]$. Accordingly, researchers have to precisely formulate questions in regard to the application on focus, choose the most adequate model, and interpret and discuss their findings in relation to the possibilities and limitations of the model [17, 71, 120]. As has been shown, recent advances in comparative placentation under an evolutionary perspective contributed essentially to provide and enlarge the pool of animal models other than the mouse. This may extend experimental approaches not only in comparison to the early processes of human placentation, but also to meet the various aspects and requirements of a long gestation and advanced developmental status of the newborn [71]. Among the pool of potential model species are in particular members of rodents, lagomorphs, ruminants, and primates that all have been used for very different purposes. The suitability and limitations of the alternative animal models have been discussed. As a key-stone, the evolutionary perspective contributes to reveal rapidly evolving aspects of placentation that may be relevant for pregnancy disease and, thus, may help to better choose appropriate models [17]. In conclusion, further investigation especially on placentation in wildlife taxa should be conducted in order to learn even more about the organismic and evolutionary plasticity of the placental system, in regard to future questions that could not be addressed with the existing models [71]. However, even though the progress in evolutionary developmental biology and related fields had stimulating effects on comparative and evolutionary perspectives on placentation especially in the last decade, current developments in science are focusing more and more on molecular aspects and one may fear the oblivion of more basic research.

\section{Conflict of Interests}

The author declares that there is no conflict of interests regarding the publication of this paper.

\section{Acknowledgments}

The current review and the ground laying, practical work in the last couple of years profited greatly from colleagues, to whom the author wants to address gratitude. Among them are especially Peter Kaufmann $(\dagger 2010)$, who shared his enthusiasms and visions in regard to trophoblast invasion, and Anthony M. Carter, who enabled joint projects on the evolution of the placental system over the last couple of years. M. Angelica Miglino and her team, including Phelipe O. Favaron, Moacir F. de Oliveira, and Carlos E. Ambrosio, provided the chance to work in Brazil and to become friends. Finally, the author wants to thank Anthony Carter, Karl Klisch, Angelica Miglino, and Manfred Ade for fruitful and encouraging comments on the paper as well as Anthony Carter for help with the English.

\section{References}

[1] P. W. Luckett, "Uses and limitations of mammalian fetal membranes and placenta for phylogenetic reconstruction," Journal of Experimental Zoology, vol. 266, no. 6, pp. 514-527, 1993.

[2] A. M. Carter, "Evolution of the placenta and fetal membranes seen in the light of molecular phylogenetics," Placenta, vol. 22, no. 10, pp. 800-807, 2001.

[3] P. Vogel, "The current molecular phylogeny of Eutherian mammals challenges previous interpretations of placental evolution," Placenta, vol. 26, no. 8-9, pp. 591-596, 2005.

[4] A. Mess and A. M. Carter, "Evolutionary transformations of fetal membrane characters in Eutheria with special reference to Afrotheria," Journal of Experimental Zoology Part B: Molecular and Developmental Evolution, vol. 306, no. 2, pp. 140-163, 2006.

[5] A. Mess and A. M. Carter, "Evolution of the placenta during the early radiation of placental mammals," Comparative Biochemistry and Physiology-A Molecular and Integrative Physiology, vol. 148, no. 4, pp. 769-779, 2007.

[6] D. E. Wildman, C. Chen, O. Erez, L. I. Grossman, M. Goodman, and R. Romero, "Evolution of the mammalian placenta revealed by phylogenetic analysis," Proceedings of the National Academy of Sciences of the United States of America, vol. 103, no. 9, pp. 3203-3208, 2006. 
[7] K. Ferner and A. Mess, "Evolution and development of fetal membranes and placentation in amniote vertebrates," Respiratory Physiology \& Neurobiology, vol. 178, no. 1, pp. 39-50, 2011.

[8] M. Garratt, J.-M. Gaillard, R. C. Brooks, and J.-F. Lemaître, "Diversification of the eutherian placenta is associated with changes in the pace of life," Proceedings of the National Academy of Sciences of the United States of America, vol. 110, no. 19, pp. 7760-7765, 2013.

[9] D. Starck, "Ontogenie und Entwicklungsphysiologie der Säugetiere," in Handbuch der Zoologie, W. Kükenthal, Ed., vol. 8, part 22, pp. 1-276, Walter Gruyter, Berlin, Germany, 1959.

[10] H. W. Mossman, Vertebrate Fetal Membranes: Comparative Ontogeny and Morphology; Evolution; Phylogenetic Significance; Basic Functions; Research Opportunities, Macmillan, London, UK, 1987.

[11] A. C. Enders, "Reasons for diversity of placental structure," Placenta, vol. 30, pp. S15-S18, 2009.

[12] A. M. Carter, "Evolution of placental function in mammals: the molecular basis of gas and nutrient transfer, hormone secretion, and immune responses," Physiological Reviews, vol. 92, no. 4, pp. 1543-1576, 2012.

[13] M. A. Miglino, F. O. Favaron, and A. M. Mess, "Review: comparative anatomy, development and functional significance of the mammalian yolk sac," Novo Science Publishers. In press.

[14] Z. C. Hou, K. N. Sterner, R. Romero et al., "Elephant transcriptome provides insights into the evolution of eutherian placentation," Genome Biology and Evolution, vol. 4, no. 5, pp. 713-725, 2012.

[15] D. Haig, "Retroviruses and the placenta," Current Biology, vol. 22, no. 15, pp. R609-R613, 2012.

[16] A. Dupressoir, C. Lavialle, and T. Heidmann, "From ancestral infectious retroviruses to bona fide cellular genes: role of the captured syncytins in placentation," Placenta, vol. 33, no. 9, pp. 663-671, 2012.

[17] E. B. Chuong, "Retroviruses facilitate the rapid evolution of the mammalian placenta," BioEssays, vol. 35, no. 10, pp. 853-861, 2013.

[18] M. J. Hemberger, "Immune balance at the foeto-maternal interface as the fulcrum of reproductive success," Journal of Reproductive Immunology, vol. 97, no. 1, pp. 36-42, 2013.

[19] M. D. Laubichler, "Das Forschungsprogramm der evolutionären Entwicklungsbiologie," in Phiolosophie der Biologie, U. Krohs and G. P. Toepfer, Eds., pp. 322-337, Suhrkamp, Berlin, Germany, 2005.

[20] L. Olsson, G. S. Levit, and U. Hossfeld, "Evolutionary developmental biology: its concepts and history with a focus on Russian and German contributions," Naturwissenschaften, vol. 97, no. 11, pp. 951-969, 2010.

[21] A. M. Carter and A. C. Enders, "Comparative aspects of trophoblast development and placentation," Reproductive Biology and Endocrinology, vol. 2, article 46, 2004.

[22] P. Chavatte-Palmer and M. Guillomot, "Comparative implantation and placentation," Gynecologic and Obstetric Investigation, vol. 64 , no. 3, pp. 166-174, 2007.

[23] A. C. Enders and A. M. Carter, "The evolving placenta: convergent evolution of variations in the endotheliochorial relationship," Placenta, vol. 33, no. 5, pp. 319-326, 2012.

[24] A. C. Enders and A. M. Carter, "Review: the evolving placenta: different developmental paths to a hemochorial relationship," Placenta, vol. 33, pp. S92-S98, 2012.
[25] A. M. Carter and A. C. Enders, "The evolution of epitheliochorial placentation," Annual Review of Animal Biosciences, vol. 1, pp. 443-467, 2013.

[26] A. Mess, "Evolutionary transformations of chorioallantoic placental characters in Rodentia with special reference to hystricognath species," Journal of Experimental Zoology Part A: Comparative Experimental Biology, vol. 299, no. 1, pp. 78-98, 2003.

[27] A. Mess, "Development of the chorioallantoic placenta in Octodon degus - a model for growth processes in caviomorph rodents?" Journal of Experimental Zoology Part B: Molecular and Developmental Evolution, vol. 308, no. 4, pp. 371-383, 2007.

[28] A. Mess, "The guinea pig placenta: model of placental growth dynamics," Placenta, vol. 28, no. 8-9, pp. 812-815, 2007.

[29] A. Mess, "The subplacenta in Octodon degus and Petromus typicus - two hystricognath rodents without significant placental lobulation," Journal of Experimental Zoology Part B: Molecular and Developmental Evolution, vol. 308, no. 2, pp. 172-188, 2007.

[30] A. Mess, "Chorioallantoic and yolk sac placentation in the dassie rat Petromus typicus and its bearing to the evolution of hystricognath Rodentia," Placenta, vol. 28, no. 11-12, pp. 12291233, 2007.

[31] M. Bonatelli, A. M. Carter, M. R. F. Machado, M. F. de Oliveira, M. C. de Lima, and M. A. Miglino, "Placentation in the paca (Agouti paca L)," Reproductive Biology and Endocrinology, vol. 3, article 9, 2005.

[32] M. F. de Oliveira, A. Mess, C. E. Ambrósio, C. A. G. Dantas, P. O. Favaron, and M. A. Miglino, "Chorioallantoic placentation in Galea spixii (Rodentia, Caviomorpha, Caviidae)," Reproductive Biology and Endocrinology, vol. 6, article 39, 2008.

[33] M. Franco de Oliveira, P. O. Favaron, C. E. Ambrósio, M. A. Miglino, and A. M. Mess, "Chorioallantoic and yolk sac placentation in Thrichomys laurentinus (Echimyidae) and the evolution of hystricognath rodents," Journal of Experimental Zoology Part B: Molecular and Developmental Evolution, vol. 318, no. 1, pp. 13-25, 2012.

[34] M. F. De Oliveira, A. M. do Vale, P. O. Favaron et al., "Development of yolk sac inversion in Galea spixii and Cavia porcellus (Rodentia, Caviidae)," Placenta, vol. 33, no. 10, pp. 878881, 2012.

[35] M. A. Flamini, E. L. Portiansky, P. O. Favaron et al., "Chorioallantoic and yolk sac placentation in the plains viscacha (Lagostomus maximus) - a caviomorph rodent with natural polyovulation," Placenta, vol. 32, no. 12, pp. 963-968, 2011.

[36] P. O. Favaron, A. M. Carter, C. E. Ambrósio et al., "Placentation in Sigmodontinae: a rodent taxon native to South America," Reproductive Biology and Endocrinology, vol. 9, article 55, 2011.

[37] P. O. Favaron, A. M. Carter, A. M. Mess, M. F. De Oliveira, and M. A. Miglino, "An unusual feature of yolk sac placentation in Necromys lasiurus (Rodentia, Cricetidae, Sigmodontinae)," Placenta, vol. 33, no. 7, pp. 578-580, 2012.

[38] P. O. Favaron, A. M. Mess, M. F. de Oliveira et al., "Morphometric analysis of the placenta in the new world mouse Necromys lasiurus (Rodentia, Cricetidae): a comparison of placental development in cricetids and murids," Reproductive Biology and Endocrinology, vol. 11, no. 1, article 10, 2013.

[39] A. M. Carter, A. C. Enders, C. J. P. Jones, P. K. Keovichit, and J. P. Hugot, "A new form of rodent placentation in the relict species, Laonastes aenigmamus (Rodentia: Diatomyidae)," Placenta, vol. 34, no. 7, pp. 548-558, 2013.

[40] B. G. Vasconcelos, P. O. Favaron, M. A. Miglino, and A. M. Mess, "Development and morphology of the inverted yolk sac in the 
guinea pig (Cavia porcellus)," Theriogenology, vol. 80, no. 6, pp. 636-641, 2013.

[41] A. M. Carter, S. M. Goodman, and A. C. Enders, "Female reproductive tract and placentation in sucker-footed bats (Chiroptera: Myzopodidae) endemic to Madagascar," Placenta, vol. 29, no. 6, pp. 484-491, 2008.

[42] A. M. Carter and A. Mess, "Evolution of the placenta and associated reproductive characters in bats," Journal of Experimental Zoology Part B: Molecular and Developmental Evolution, vol. 310, no. 5, pp. 428-449, 2008.

[43] A. C. Enders, C. J. P. Jones, P. J. Taylor, and A. M. Carter, "Placentation in the Egyptian slit-faced bat Nycteris thebaica (Chiroptera: Nycteridae)," Placenta, vol. 30, no. 9, pp. 792-799, 2009.

[44] L. C. Rezende, C. G. Barbeito, P. O. Favaron, A. Mess, and M. A. Miglino, "The fetomaternal interface in the placenta of three species of armadillos (Eutheria, Xenarthra, Dasypodidae)," Reproductive Biology and Endocrinology, vol. 10, article 38, 2012.

[45] A. M. Mess, P. O. Favaron, C. Pfarrer et al., "Placentation in the anteaters Myrmecophaga tridactyla and Tamandua tetradactyla (Eutheria, Xenarthra)," Reproductive Biology and Endocrinology, vol. 10, article 102, 2012.

[46] A. M. Carter and A. C. Enders, "Placentation in mammals once grouped as insectivores," The International Journal of Developmental Biology, vol. 54, no. 2-3, pp. 483-493, 2010.

[47] A. C. Enders, T. N. Blankenship, S. M. Goodman, V. Soarimalala, and A. M. Carter, "PPlacental diversity in malagasy tenrecs: placentation in shrew tenrecs (Microgale spp.), the mole-like rice tenrec (Oryzorictes hova) and the web-footed tenrec (Limnogale mergulus)," Placenta, vol. 28, no. 7, pp. 748759, 2007.

[48] J. N. Rutherford, "Toward a nonhuman primate model of fetal programming: phenotypic plasticity of the common marmoset fetoplacental complex," Placenta, vol. 33, pp. S35-S39, 2012.

[49] S. Siniza, D. G. Lupiañez, R. Jiménez, and U. Zeller, "Morphology and ultrastructure of the chorioallantoic placenta of the Iberian mole (Talpa occidentalis) with special reference to heterophagous areolas and the nature of interhaemal barrier," Journal of Anatomy, vol. 221, no. 2, pp. 164-173, 2012.

[50] K. Ferner, S. Siniza, and U. Zeller, "The placentation of eulipotyphla-reconstructing a morphotype of the mammalian placenta," Journal of Morphology, vol. 275, no. 10, pp. 1122-1144, 2014.

[51] F. B. P. Wooding, J. Kimura, and A. J. Forhead, "Functional immunocytochemistry of Tragulus placenta: implications for ruminant evolution," Placenta, vol. 35, no. 5, pp. 305-310, 2014.

[52] A. M. Carter and A. M. Mess, "Conservation of placentation during the tertiary radiation of mammals in South America," Journal of Morphology, vol. 274, no. 5, pp. 557-569, 2013.

[53] A. M. Carter, "Comparative studies of placentation and immunology in non-human primates suggest a scenario for the evolution of deep trophoblast invasion and an explanation for human pregnancy disorders," Reproduction, vol. 141, no. 4, pp. 391-396, 2011.

[54] A. M. Carter and R. Pijnenborg, "Evolution of invasive placentation with special reference to non-human primates," Best Practice \& Research: Clinical Obstetrics \& Gynaecology, vol. 25, no. 3, pp. 249-257, 2011.

[55] R. Pijnenborg, L. Vercruysse, and A. M. Carter, "Deep trophoblast invasion and spiral artery remodelling in the placental bed of the lowland gorilla," Placenta, vol. 32, no. 8, pp. 586-591, 2011.
[56] R. Pijnenborg, L. Vercruysse, and A. M. Carter, "Deep trophoblast invasion and spiral artery remodelling in the placental bed of the chimpanzee," Placenta, vol. 32, no. 5, pp. 400-408, 2011.

[57] A. M. Carter, T. N. Blankenship, A. C. Enders, and P. Vogel, "The fetal membranes of the otter shrews and a synapomorphy for afrotheria," Placenta, vol. 27, no. 2-3, pp. 258-268, 2006.

[58] M. G. Elliot and B. J. Crespi, "Phylogenetic evidence for early hemochorial placentation in eutheria," Placenta, vol. 30, no. 11, pp. 949-967, 2009.

[59] D. E. Wildman, "Review: toward an integrated evolutionary understanding of the mammalian placenta," Placenta, vol. 32, no. 2, pp. S142-S145, 2011.

[60] I. Capellini, “The evolutionary significance of placental interdigitation in mammalian reproduction: contributions from comparative studies," Placenta, vol. 33, no. 10, pp. 763-768, 2012.

[61] A. Moffett and C. Loke, "Immunology of placentation in eutherian mammals," Nature Reviews Immunology, vol. 6, no. 8, pp. 584-594, 2006.

[62] D. Emera, R. Romero, and G. Wagner, "The evolution of menstruation: a new model for genetic assimilation: explaining molecular origins of maternal responses to fetal invasiveness," BioEssays, vol. 34, no. 1, pp. 26-35, 2012.

[63] A. L. Fowden and T. Moore, "Maternal-fetal resource allocation: co-operation and conflict," Placenta, vol. 33, no. 2, pp. el1-e15, 2012.

[64] R. M. Lewis, J. K. Cleal, and M. A. Hanson, "Review: placenta, evolution and lifelong health," Placenta, vol. 33, pp. S28-S32, 2012.

[65] E. J. Crosley, M. G. Elliot, J. K. Christians, and B. J. Crespi, "Placental invasion, preeclampsia risk and adaptive molecular evolution at the origin of the great apes: evidence from genomewide analyses," Placenta, vol. 34, no. 2, pp. 127-132, 2013.

[66] J. S. Hunt and M. G. Petroff, "IFPA senior award lecture: reproductive immunology in perspective-reprogramming at the maternal-fetal interface," Placenta, vol. 34, pp. S52-S55, 2013.

[67] E. C. Teeling and S. B. Hedges, "Making the impossible possible: rooting the tree of placental mammals," Molecular Biology and Evolution, vol. 30, no. 9, pp. 1999-2000, 2013.

[68] A. M. Carter, "Animal models of human placentation-a review," Placenta, vol. 28, pp. S41-S47, 2007.

[69] J. L. James, A. M. Carter, and L. W. Chamley, "Human placentation from nidation to 5 weeks of gestation. Part II: tools to model the crucial first days," Placenta, vol. 33, no. 5, pp. 335-342, 2012.

[70] D. A. Clark, "The use and misuse of animal analog models of human pregnancy disorders," Journal of Reproductive Immunology C, vol. 103, pp. 1-8, 2014.

[71] A. M. Carter and A. M. Mess, "Mammalian placentation: implications for animal models," in Pathobiology of Human Disease: A Dynamic Encyclopedia of Disease Mechanisms, L. M. McManus and R. N. Mitchell, Eds., Elsevier, Berlin, Germany, 2014.

[72] A. E. Guttmacher, Y. T. Maddox, and C. Y. Spong, "The Human Placenta Project: placental structure, development, and function in real time," Placenta, vol. 35, no. 5, pp. 303-304, 2014.

[73] W. Westheide and R. Rieger, Spezielle Zoologie. Teil 2: Wirbeloder Schädeltiere, Spektrum, Elsevier, München, Germany, 2010. 
[74] A. Mess, D. G. Blackburn, and U. Zeller, "Evolutionary transformations of fetal membranes and reproductive strategies," Journal of Experimental Zoology Part A: Comparative Experimental Biology, vol. 299, no. 1, pp. 3-12, 2003.

[75] D. E. Wilson and D. M. Reeder, Mammal Species of the World, Johns Hopkins University Press, Baltimore, Md, USA, 2005.

[76] M. A. O'Leary, J. I. Bloch, J. J. Flynn et al., "The placental mammal ancestor and the Post-K-Pg radiation of placentals," Science, vol. 339, no. 6120, pp. 662-667, 2013.

[77] M. J. Stanhope, V. G. Waddell, O. Madsen et al., "Molecular evidence for multiple origins of Insectivora and for a new order of endemic African insectivore mammals," Proceedings of the National Academy of Sciences of the United States of America, vol. 95, no. 17, pp. 9967-9972, 1998.

[78] O. Madsen, M. Scally, C. J. Douady et al., "Parallel adaptive radiations in two major clades of placental mammals," Nature, vol. 409, no. 6820, pp. 610-614, 2001.

[79] W. J. Murphy, E. Eizirik, S. J. O’Brien et al., "Resolution of the early placental mammal radiation using Bayesian phylogenetics," Science, vol. 294, no. 5550, pp. 2348-2351, 2001.

[80] P. J. Waddell, H. Kishino, and R. Ota, "A phylogenetic foundation for comparative mammalian genomics," Genome information, vol. 12, pp. 141-154, 2001.

[81] M. S. Springer, M. J. Stanhope, O. Madsen, and W. W. de Jong, "Molecules consolidate the placental mammal tree," Trends in Ecology and Evolution, vol. 19, no. 8, pp. 430-438, 2004.

[82] M. S. Springer, W. J. Murphy, E. Eizirik, and S. J. O'Brien, "Molecular evidence for major placental clades," in The Rise of Placental Mammals: Origins and Relationships of the Major Extant Clades, K. D. Rose and J. D. Archibald, Eds., pp. 37-49, Johns Hopkins University Press, Baltimore, Md, USA, 2005.

[83] R. W. Meredith, J. E. Janečka, J. Gatesy et al., "Impacts of the cretaceous terrestrial revolution and KPg extinction on mammal diversification," Science, vol. 334, no. 6055, pp. 521$524,2011$.

[84] J. D. Archibald, “Timing and biogeography of the eutherian radiation: fossils and molecules compared," Molecular Phylogenetics and Evolution, vol. 28, no. 2, pp. 350-359, 2003.

[85] M. J. Novacek, A. R. Wyss, and M. C. McKenna, "The major groups of eutherian mammals," in The Phylogeny and Classification of the Tetrapods Volume 2: Mammals, M. J. Benton, Ed., pp. 31-71, Clarendon Press, Oxford, UK, 1988.

[86] J. G. M. Thewissen, L. N. Cooper, M. T. Clementz, S. Bajpai, and B. N. Tiwari, "Whales originated from aquatic artiodactyls in the Eocene epoch of India," Nature, vol. 450, no. 7173, pp. 11901194, 2007.

[87] S. B. McDowell, "The greater antillean insectivores," Bulletin of the American Museum of Natural History, vol. 115, pp. 115-213, 1958.

[88] R. J. Asher, M. J. Novacek, and J. H. Geisler, "Relationships of endemic African mammals and their fossil relatives based on morphological and molecular evidence," Journal of Mammalian Evolution, vol. 10, no. 1-2, pp. 131-164, 2003.

[89] M. R. E. Symonds, "Phylogeny and life histories of the "insectivora": controversies and consequences," Biological Reviews of the Cambridge Philosophical Society, vol. 80, no. 1, pp. 93-128, 2005.

[90] O. R. Bininda-Emonds, M. Cardillo, K. E. Jones et al., "The delayed rise of present-day mammals," Nature, vol. 446, pp. 507$512,2007$.
[91] J. Romiguier, V. Ranwez, F. Delsuc, N. Galtier, and E. J. P. Douzery, "Less is more in mammalian phylogenomics: AT-rich genes minimize tree conflicts and unravel the root of placental mammals," Molecular Biology and Evolution, vol. 30, no. 9, pp. 2134-2144, 2013.

[92] E. C. Amoroso, "Placentation," in Marshall's Physiology of Reproduction, A. S. Parkes, Ed., vol. 2, pp. 127-311, Longmans Green, London, UK, 1952.

[93] D. G. Blackburn, "Evolution of vertebrate viviparity and specializations for fetal nutrition: a quantitative and qualitative analysis," Journal of Morphology, 2014.

[94] J. R. Stewart, "Fetal nutrition in lecithotrophic squamate reptiles: toward a comprehensive model for evolution of viviparity and placentation," Journal of Morphology, vol. 274, no. 7, pp. 824-843, 2013.

[95] B. Crespi and C. Semeniuk, "Parent-offspring conflict in the evolution of vertebrate reproductive mode," The American Naturalist, vol. 163, no. 5, pp. 635-653, 2004.

[96] D. W. Zeh and J. A. Zeh, "Reproductive mode and speciation: the viviparity-driven conflict hypothesis," Bioessays, vol. 22, pp. 938-946, 2000.

[97] F. B. Wooding and G. J. Burton, Comparative Placentation: Structures, Function and Evolution, Springer, Berlin, Germany, 2008.

[98] O. Grosser, Eihäute und der Placenta, Wilhelm Braumüller, Vienna, Austria, 1909.

[99] A. M. Carter, "Evolution of factors affecting placental oxygen transfer," Placenta, vol. 30, pp. 19-25, 2009.

[100] R. Pijnenborg, L. Vercruysse, and M. Hanssens, "Fetal-maternal conflict, trophoblast invasion, preeclampsia, and the red queen," Hypertension in Pregnancy, vol. 27, no. 2, pp. 183-196, 2008.

[101] A. Mess, N. Zaki, M. Kadyrov, H. Korr, and P. Kaufmann, "Caviomorph placentation as a model for trophoblast invasion," Placenta, vol. 28, no. 11-12, pp. 1234-1238, 2007.

[102] B. Huppertz, D. Ghosh, and J. Sengupta, "An integrative view on the physiology of human early placental villi," Progress in Biophysics and Molecular Biology, vol. 114, no. 1, pp. 33-48, 2014.

[103] J. A. Lillegraven, "Polarities in mammalian evolution seen through homologs of the inner cell mass," Journal of Mammalian Evolution, vol. 10, no. 4, pp. 277-333, 2003.

[104] K. Klisch and A. Mess, "Evolutionary differentiation of cetartiodactyl placentae in the light of the viviparity-driven conflict hypothesis," Placenta, vol. 28, no. 4, pp. 353-360, 2007.

[105] L. H. Hoffman and F. B. Wooding, "Giant and binucleate trophoblast cells of mammals," Journal of Experimental Zoology, vol. 266, no. 6, pp. 559-577, 1993.

[106] C. D. Pfarrer, P. Hirsch, M. Guillomot, and R. Leiser, "Interaction of integrin receptors with extracellular matrix is involved in trophoblast giant cell migration in bovine placentomes," Placenta, vol. 24, no. 6, pp. 588-597, 2003.

[107] G. Sheng and A. C. Foley, "Diversification and conservation of the extraembryonic tissues in mediating nutrient uptake during amniote development," Annals of the New York Academy of Sciences, vol. 1271, no. 1, pp. 97-103, 2012.

[108] M. H. Baron, "Concise review: early embryonic erythropoiesis: not so primitive after all," Stem Cells, vol. 31, no. 5, pp. 849-856, 2013.

[109] J. D. Boyd and W. J. Hamilton, The Human Placenta, Heffer, Cambridge, UK, 1970.

[110] C. C. Morgan, P. G. Foster, A. E. Webb, D. Pisani, J. O. McInerney, and M. J. O'Connell, "Heterogeneous models place 
the root of the placental mammal phylogeny," Molecular Biology and Evolution, vol. 30, no. 9, pp. 2145-2156, 2013.

[111] L. P. Bergqvist, É. A. L. Abrantes, and L. D. S. Avilla, "The Xenarthra (Mammalia) of São José de Itaboraí basin (upper Paleocene, Itaboraian), Rio de Janeiro, Brazil," Geodiversitas, vol. 26, no. 2, pp. 323-337, 2004.

[112] M. dos Reis, J. Inoue, M. Hasegawa, R. J. Asher, P. C. J. Donoghue, and Z. Yang, "Phylogenomic datasets provide both precision and accuracy in estimating the timescale of placental mammal phylogeny," Proceedings of the Royal Society B: Biological Sciences, vol. 279, no. 1742, pp. 3491-3500, 2012.

[113] J. J. Flynn, R. Charrier, D. A. Croft, and A. R. Wyss, "Cenozoic Andean faunas: shedding new light on South American mammal evolution, biogeography, environments and tectonics," in Bones Clones and Biomes - The History and Geography of Recent Neotropical Mammals, B. D. Patterson and L. P. Costa, Eds., pp. 50-75, University of Chicago Press, Chicago, Ill, USA, 2012.

[114] T. J. Gaudin and H. G. McDonald, "Morphology-based investigations of the phylogenetic relationships among extant and fossil xenarthrans," in The Biology of the Xenarthra, S. F. L. Vizcaíno and W. J. Gainesville, Eds., pp. 24-36, University Press of Florida, Gainesville, Fla, USA, 2008.

[115] A. C. Enders, "Development and structure of the villous haemochorial placenta of the nine-banded armadillo (Dasypus novemcinctus)," Journal of anatomy, vol. 94, pp. 34-45, 1960.

[116] A. C. Enders, "Electron microscopic observations on the villous haemochorial placenta of the nine-banded armadillo (Dasypus novemcinctus)," Journal of Anatomy, vol. 94, pp. 205-215, 1960.

[117] A. C. Enders, "Placentation in armadillos, with emphasis on development of the placenta in polyembryonic species," in The Biology of the Xenarthra, S. F. L. Vizcaíno and W. J. Gainesville, Eds., pp. 172-180, University Press of Florida, Gainesville, Fla, USA, 2008.

[118] B. F. King, P. B. N. Pinheiro, and R. L. Hunter, "The fine structure of the placental labyrinth in the sloth, Bradypus tridactylus," Anatomical Record, vol. 202, no. 1, pp. 15-22, 1982.

[119] G. B. Wislocki, "On the placentation of the two-toed anteater (Cyclopes didactylus)," Anatomical Record, vol. 39, pp. 69-79, 1928.

[120] K. Benirschke, G. J. Burton, and R. N. Baergen, Pathology of the Human Placenta, Springer, Berlin, Germany, 2012.

[121] H. Becher, "Placenta und Uterusschleimhaut von Tamandua tetradactya (Myrmecophaga)," Morphologisches Jahrbuch, vol. 67, pp. 381-458, 1931.

[122] E. W. Walls, "Myrmecophaga jubata: an embryo with placenta," Journal of Anatomy, vol. 73, pp. 311-317, 1939.

[123] V. C. Adamoli, P. D. Cetica, M. S. Merani, and A. J. Solari, "Comparative morphologic placental types in dasypodidae (Chaetophractus villosus, Cabassous chacoensis, Tolypeutes matacus and Dasypus hybridus)," Biocell, vol. 25, no. 1, pp. 17-22, 2001.

[124] G. G. Simpson, "The principles of classification and a classification of mammals," Bulletin of the American Museum of Natural History, vol. 85, pp. 1-350, 1945.

[125] M. S. Springer, G. C. Cleven, O. Madsen et al., "Endemic African mammals shake the phylogenetic tree," Nature, vol. 388, no. 6637, pp. 61-64, 1997.

[126] E. R. Seiffert, "A new estimate of afrotherian phylogeny based on simultaneous analysis of genomic, morphological, and fossil evidence," BMC Evolutionary Biology, vol. 7, article 224, 2007.
[127] T. J. Robinson and E. R. Seiffert, "Afrotherian origins and interrelationships: new views and future prospects," Current Topics in Developmental Biology, vol. 63, pp. 37-60, 2004.

[128] R. J. Asher and T. Lehmann, "Dental eruption in afrotherian mammals," BMC Biology, vol. 6, article 14, 2008.

[129] E. Gheerbrant, M. Amaghzaz, B. Bouya, F. Goussard, and C. Letenneur, "Ocepeia (middle Paleocene of Morocco): the oldest skull of an afrotherian mammal," PLoS ONE, vol. 9, no. 2, Article ID e89739, 2014.

[130] IUCN Afrotheria Specialist Group, http://www.afrotheria.net/.

[131] B. M. Hallström, A. Schneider, S. Zoller, and A. Janke, "A genomic approach to examine the complex evolution of Laurasiatherian mammals," PLoS ONE, vol. 6, no. 12, Article ID e28199, 2011.

[132] J.-Y. Hu, Y.-P. Zhang, and L. Yu, "Summary of Laurasiatheria (mammalia) phylogeny," Dongwuxue Yanjiu, vol. 33, no. 5-6, pp. E65-E74, 2012.

[133] M. Nikaido, A. P. Rooney, and N. Okada, "Phylogenetic relationships among cetartiodactyls based on insertions of short and long interpersed elements: hippopotamuses are the closest extant relatives of whales," Proceedings of the National Academy of Sciences of the United States of America, vol. 96, no. 18, pp. 10261-10266, 1999.

[134] X. Zhou, S. Xu, J. Xu, B. Chen, K. Zhou, and G. Yang, "Phylogenomic analysis resolves the interordinal relationships and rapid diversification of the laurasiatherian mammals," Systematic Biology, vol. 61, no. 1, pp. 150-164, 2011.

[135] E. C. Teeling, M. S. Springer, O. Madsen, P. Bates, S. J. O’Brien, and W. J. Murphy, "A molecular phylogeny for bats illuminates biogeography and the fossil record," Science, vol. 307, no. 5709, pp. 580-584, 2005.

[136] J. J. Rasweiler and N. K. Badwaik, "Anatomy and physiology of the female reproductive tract," in Reproductive Biology of Bats, E. G. Crichton and P. H. Krutzch, Eds., pp. 157-219, Academic Press, San Diego, Calif, USA, 2000.

[137] F. T. V. Pereira, L. J. Oliveira, R. S. N. Barreto et al., "Fetalmaternal interactions in the synepitheliochorial placenta using the eGFP cloned cattle model," PLoS ONE, vol. 8, no. 5, Article ID e64399, 2013.

[138] R. V. Anthony, A. N. Scheaffer, C. D. Wright, and T. R. Regnault, "Ruminant models of prenatal growth restriction," Reproduction, vol. 61, pp. 183-194, 2003.

[139] J. S. Barry and R. V. Anthony, “The pregnant sheep as a model for human pregnancy," Theriogenology, vol. 69, no. 1, pp. 55-67, 2008.

[140] D. H. Steven, Ed., Comparative Placentation: Essays in Structure and Function, Academic Press, London, UK, 1975.

[141] R. Leiser, C. Krebs, B. Ebert, and V. Dantzer, "Placental vascular corrosion cast studies: a comparison between ruminants and humans," Microscopic Research Techniques, vol. 38, pp. 76-87, 1997.

[142] G. Meschia, J. R. Cotter, C. S. Breathnach, and D. H. Barron, "The diffusibility of oxygen across the sheep placenta," Quarterly Journal of Experimental Physiology and Cognate Medical Sciences, vol. 50, no. 4, pp. 466-480, 1965.

[143] A. M. Carter, "Placental oxygen consumption. Part I: in vivo studies-a review," Placenta, vol. 21, no. 1, pp. S31-S37, 2000.

[144] W. W. Hay Jr., "In vivo measurements of placental transport and metabolism," Proceedings of the Nutrition Society, vol. 50, no. 2, pp. 355-362, 1991. 
[145] R. I. Jensen, A. M. Carter, O. Skøtt, and B. L. Jensen, "Adrenomedullin expression during hypoxia in fetal sheep," Acta Physiologica Scandinavica, vol. 183, no. 2, pp. 219-228, 2005.

[146] Y. Shufaro and N. Laufer, "Epigenetic concerns in assisted reproduction: update and critical review of the current literature," Fertility and Sterility, vol. 99, no. 3, pp. 605-606, 2013.

[147] K. J. Go, J. C. Patel, and D. L. Cunningham, "The role of assisted reproductive technology in the management of recurrent pregnancy loss," Current Opinion in Endocrinology, Diabetes and Obesity, vol. 16, no. 6, pp. 459-463, 2009.

[148] A. Eroglu and L. C. Layman, "Role of ART in imprinting disorders," Seminars in Reproductive Medicine, vol. 30, no. 2, pp. 92-104, 2012.

[149] M. I. Cedars, "National reporting of in vitro fertilization success rates: how do we get patients useful information?" Fertility and Sterility, vol. 100, no. 5, pp. 1210-1211, 2013.

[150] N. Okun and S. Sierra, "Pregnancy outcomes after assisted human reproduction," Journal of Obstetrics and Gynaecology Canada, vol. 36, no. 1, pp. 64-83, 2014.

[151] N. R. Vulliemoz, E. McVeigh, and J. Kurinczuk, "In vitro fertilisation: perinatal risks and early childhood outcomes," Human Fertility, vol. 15, pp. 62-68, 2012.

[152] R. Ramasamy, L. I. Lipshultz, and D. J. Lamb, "Cancer risk among children born after assisted conception," The New England Journal of Medicine, vol. 370, p. 975, 2014.

[153] J. L. Edwards, F. N. Schrick, M. D. McCracken et al., "Cloning adult farm animals: a review of the possibilities and problems associated with somatic cell nuclear transfer," The American Journal of Reproductive Immunology, vol. 50, no. 2, pp. 113-123, 2003.

[154] F. V. Meirelles, E. H. Birgel Jr., F. Perecin et al., "Delivery of cloned offspring: experience in Zebu cattle (Bos indicus)," Reproduction, Fertility and Development, vol. 22, no. 1, pp. 8897, 2010.

[155] T. H. C. De Bem, M. R. Chiaratti, R. Rochetti et al., "Viable calves produced by somatic cell nuclear transfer using meioticblocked oocytes," Cellular Reprogramming, vol. 13, no. 5, pp. 419-429, 2011.

[156] J. R. Hill, R. C. Burghardt, K. Jones et al., "Evidence for placental abnormality as the major cause of mortality in first-trimester somatic cell cloned bovine fetuses," Biology of Reproduction, vol. 63, no. 6, pp. 1787-1794, 2000.

[157] M. A. Miglino, F. T. V. Pereira, J. A. Visintin et al., "Placentation in cloned cattle: structure and microvascular architecture," Theriogenology, vol. 68, no. 4, pp. 604-617, 2007.

[158] F. Constant, M. Guillomot, Y. Heyman et al., "Large offspring or large placenta syndrome? Morphometric analysis of late gestation bovine placentomes from somatic nuclear transfer pregnancies complicated by hydrallantois," Biology of Reproduction, vol. 75, no. 1, pp. 122-130, 2006.

[159] M. L. V. Alberto, F. V. Meirelles, F. Perecin et al., "Development of bovine embryos derived from reproductive techniques," Reproduction, Fertility and Development, vol. 25, no. 6, pp. 907917, 2013.

[160] P. Chavatte-Palmer, S. Camous, H. Jammes, N. Le Cleac'H, M. Guillomot, and R. S. F. Lee, "Review: placental perturbations induce the developmental abnormalities often observed in bovine somatic cell nuclear transfer," Placenta, vol. 33, pp. S99S104, 2012.
[161] P. C. Maiorka, A. Mess, P. O. Favaron, and M. A. Miglino, "Vascular alterations are key for developmental problems in the pre- and postnatal phases of cloned bovines," PLOS ONE. Submitted.

[162] C. D. Pfarrer, S. D. Ruziwa, H. Winther et al., "Localization of vascular endothelial growth factor (VEGF) and its receptors VEGFR-1 and VEGFR-2 in bovine placentomes from implantation until term," Placenta, vol. 27, no. 8, pp. 889-898, 2006.

[163] D. B. Campos, P. C. Papa, J. E. B. Marques Jr. et al., "Somatic cell nuclear transfer is associated with altered expression of angiogenic factor systems in bovine placentomes at term," Genetics and Molecular Research, vol. 9, no. 1, pp. 309-323, 2010.

[164] M. Kutzler, L. Sahlfeld, and E. Fellows, "Who let the dogs in: a canine trophoblast invasion model for pre-eclampsia," Reproduction in Domestic Animals, vol. 47, no. 6, pp. 186-189, 2012.

[165] L. Sahlfeld, T. Hazzard, and M. Kutzler, "Cellular characteristics of cultured canine trophoblasts," Reproduction in Domestic Animals, vol. 47, no. 6, pp. 161-164, 2012.

[166] J. O. Kriegs, G. Churakov, M. Kiefmann, U. Jordan, J. Brosius, and J. Schmitz, "Retroposed elements as archives for the evolutionary history of placental mammals," PLoS biology, vol. 4, no. 4, article e91, 2006.

[167] R. J. Asher, N. Bennett, and T. Lehmann, "The new framework for understanding placental mammal evolution," BioEssays, vol. 31, no. 8, pp. 853-864, 2009.

[168] M. S. Springer, R. W. Meredith, J. E. Janecka, and W. J. Murphy, “The historical biogeography of mammalia," Philosophical Transactions of the Royal Society B: Biological Sciences, vol. 366, no. 1577, pp. 2478-2502, 2011.

[169] R. J. Asher, J. Meng, J. R. Wible et al., "Stem lagomorpha and the antiquity of glires," Science, vol. 307, no. 5712, pp. 1091-1094, 2005.

[170] J. O. Kriegs, A. Zemann, G. Churakov et al., "Retroposon insertions provide insights into deep Lagomorph evolution," Molecular Biology and Evolution, vol. 27, no. 12, pp. 2678-2681, 2010.

[171] A. Mess, "Character transformations and their functional significance as a key to the evolution of hystricognath Rodentia," Pesquisa Veterinaria Brasileira, vol. 31, no. 12, pp. 1108-1115, 2011.

[172] W. P. Luckett, "Superordinal and intraordinal affinities of rodents: developmental evidence from the dentition and placentation," in Evolutionary Relationships among Rodents, W. P. Luckett and J.-L. Hartenberger, Eds., vol. 92 of NATO ASI-Series, pp. 227-276, Plenum Press, New York, NY, USA, 1985.

[173] M. Ade, "Macroscopic study on the rhinarium of the Lagomorpha. With special reference to the glires hypothesis," Mitteilungen aus dem Museum für Naturkunde, Zoologische Reihe, vol. 75, pp. 191-216, 1999.

[174] S. Frahnert, "Morphology of the glires ancestral rostral cranium and its implications for the monophyly of this clade," Mitteilungen aus dem Museum für Naturkunde, Zoologische Reihe, vol. 75, pp. 229-246, 1999.

[175] A. Mess, "The rostral nasal skeleton of hystricognath rodents: evidence on their phylogenetic interrelationships," Mitteilungen aus dem Museum für Naturkunde, Zoologische Reihe, vol. 75, pp. 19-35, 1999.

[176] A. Mess, "Evolutionary differentiation of the rostral nasal skeleton within Glires. A review with new data on lagomorph ontogeny," Mitteilungen aus dem Museum für Naturkunde, Zoologische Reihe, vol. 75, pp. 221-232, 1999. 
[177] J. Meng, A. R. Wyss, M. R. Dawson, and R. Zhai, "Primitive fossil rodent from inner mongolia and its implications for mammalian phylogeny," Nature, vol. 370, no. 6485, pp. 134-136, 1994.

[178] W. P. Luckett, "Morphogenesis of the placenta and fetal membranes of the tree shrews (family Tupaiidae).," American Journal of Anatomy, vol. 123, no. 3, pp. 385-428, 1968.

[179] P. Kaufmann, M. Luckhardt, and W. Elger, "The structure of the tupaia placenta- II. Ultrastructure," Anatomy and Embryology, vol. 171, no. 2, pp. 211-221, 1985.

[180] K. Theiler, The House Mouse: Development and Normal Stages from Fertilisation to 4 Weeks of Age, Springer, New York, NY, USA, 1972.

[181] S. L. Adamson, Y. Lu, K. J. Whiteley et al., "Interactions between trophoblast cells and the maternal and fetal circulation in the mouse placenta," Developmental Biology, vol. 250, no. 2, pp. 358373, 2002.

[182] P. Georgiades, A. C. Fergyson-Smith, and G. J. Burton, "Comparative developmental anatomy of the murine and human definitive placentae," Placenta, vol. 23, no. 1, pp. 3-19, 2002.

[183] J. C. Cross, D. Baczyk, N. Dobric et al., "Genes, development and evolution of the placenta," Placenta, vol. 24, no. 2-3, pp. 123-130, 2003.

[184] M. Hemberger, T. Nozaki, M. Masutani, and J. C. Cross, "Differential expression of angiogenic and vasodilatory factors by invasive trophoblast giant cells depending on depth of invasion," Developmental Dynamics, vol. 227, no. 2, pp. 185-191, 2003.

[185] E. D. Watson and J. C. Cross, "Development of structures and transport functions in the mouse placenta," Physiology, vol. 20, no. 3, pp. 180-193, 2005.

[186] D. G. Simmons, A. L. Fortier, and J. C. Cross, "Diverse subtypes and developmental origins of trophoblast giant cells in the mouse placenta," Developmental Biology, vol. 304, no. 2, pp. 567578, 2007.

[187] D. Hu and J. C. Cross, "Development and function of trophoblast giant cells in the rodent placenta," International Journal of Developmental Biology, vol. 54, no. 2-3, pp. 341-354, 2010.

[188] R. M. Roberts and S. J. Fisher, "Trophoblast stem cells," Biology of Reproduction, vol. 84, no. 3, pp. 412-421, 2011.

[189] O. R. Vaughan, A. N. Sferruzzi-Perri, P. M. Coan, and A. L. Fowden, "Environmental regulation of placental phenotype: Implications for fetal growth," Reproduction, Fertility and Development, vol. 24, no. 1, pp. 80-96, 2011.

[190] M. R. Dilworth and C. P. Sibley, "Review: transport across the placenta of mice and women," Placenta, vol. 34, pp. S34-S39, 2013.

[191] M. Gasperowicz, M. Yampolsky, and C. M. Salafia, "Metabolic scaling law for mouse fetal and placental weight," Placenta, vol. 34, no. 11, pp. 1099-1101, 2013.

[192] H.-P. Li, X. Chen, and M.-Q. Li, "Gestational diabetes induces chronic hypoxia stress and excessive inflammatory response in murine placenta," International Journal of Clinical and Experimental Pathology, vol. 6, no. 4, pp. 650-659, 2013.

[193] P. A. Latos and M. Hemberger, "Review: the transcriptional and signalling networks of mouse trophoblast stem cells," Placenta, vol. 35, pp. S81-S85, 2014.

[194] A. Rai and J. C. Cross, "Development of the hemochorial maternal vascular spaces in the placenta through endothelial and vasculogenic mimicry," Developmental Biology, vol. 387, no. 2, pp. 131-141, 2014.
[195] M. Duval, "Le placenta des rongeurs. III. Le placenta de la souris et du rat," Journal of Anatomy and Physiology, vol. 27, pp. 24-73, 344-395, 515-612, 1891.

[196] W. P. Jollie, "The fine structure of the interhemal membrane of the rat chorioallantoic placenta during prolonged pregnancy," Anatomical Record, vol. 184, no. 1, pp. 73-89, 1976.

[197] J. Metz, "On the developing rat placenta. I. Differentiation and junctional alterations of labyrinthine layers II and III," Anatomy and Embryology, vol. 159, no. 3, pp. 289-305, 1980.

[198] S. Caluwaerts, L. Vercruysse, C. Luyten, and R. Pijnenborg, "Endovascular trophoblast invasion and associated structural changes in uterine spiral arteries of the pregnant rat," Placenta, vol. 26, no. 7, pp. 574-584, 2005.

[199] L. Vercruysse, S. Caluwaerts, C. Luyten, and R. Pijnenborg, "Interstitial trophoblast invasion in the decidua and mesometrial triangle during the last third of pregnancy in the rat," Placenta, vol. 27, no. 1, pp. 22-33, 2006.

[200] L. Hering, F. Herse, N. Geusens et al., "Effects of circulating and local uteroplacental angiotensin ii in rat pregnancy," Hypertension, vol. 56, no. 2, pp. 311-318, 2010.

[201] A. Serman and L. Serman, "Development of placenta in a rodent-model for human placentation," Frontiers in Bioscience-Elite, vol. 3, no. 1, pp. 233-239, 2011.

[202] T. G. Zybina, G. I. Stein, and E. V. Zybina, "Endopolyploid and proliferating trophoblast cells express different patterns of intracellular cytokeratin and glycogen localization in the rat placenta," Cell Biology International, vol. 35, no. 7, pp. 649-655, 2011.

[203] B. M. Fonseca, G. Correia-da-Silva, and N. A. Teixeira, "The rat as an animal model for fetoplacental development: a reappraisal of the post-implantation period," Reproductive Biology, vol. 12, no. 2, pp. 97-118, 2012.

[204] J. S. Gilbert, A. J. Bauer, A. Gingery, C. T. Banek, and S. Chasson, "Circulating and utero-placental adaptations to chronic placental ischemia in the rat," Placenta, vol. 33, no. 2, pp. 100-105, 2012.

[205] M. J. Soares, D. Chakraborty, M. A. Karim Rumi, T. Konno, and S. J. Renaud, "Rat placentation: an experimental model for investigating the hemochorial maternal-fetal interface," Placenta, vol. 33, no. 4, pp. 233-243, 2012.

[206] M. Shin, H. Hino, M. Tamura et al., "Thrombomodulin improves maternal and fetal conditions in an experimental preeclampsia rat model," Journal of Obstetrics and Gynaecology Research, vol. 40, pp. 1226-1234, 2014.

[207] A. C. Enders, "A comparative study of the fine structure of the trophoblast in several hemochorial placentas," The American Journal of Anatomy, vol. 116, pp. 29-67, 1965.

[208] B. A. Croy, Z. Chen, A. P. Hofmann, E. M. Lord, A. L. Sedlacek, and S. A. Gerber, "The imaging of vascular development in early mouse decidua and its association with leukocytes and trophoblasts," Biology of Reproduction, vol. 87, no. 5, article 125, 2012.

[209] A. Robson, L. K. Harris, B. A. Innes et al., "Uterine natural killer cells initiate spiral artery remodeling in human pregnancy," The FASEB Journal, vol. 26, no. 12, pp. 4876-4885, 2012.

[210] P. Parham and A. Moffett, "Variable NK cell receptors and their MHC class I ligands in immunity, reproduction and human evolution," Nature Reviews Immunology, vol. 13, no. 2, pp. 133144, 2013

[211] R. Lavocat, "La systématique des Rongeurs hystricomorphes et la dérive des continents," Comptes Rendus de l'Académie des Sciences, Série D: Sciences Naturelles, vol. 269, no. 16, pp. 14961497, 1969. 
[212] D. H. Tarling, "The geologic evolution of South America with special reference to the last 200 million years," in Evolutionary Biology of the New World Monkeys and Continental Drift, R. L. Ciochon and A. B. Chiarelli, Eds., pp. 1-41, Plenum Press, New York, NY, USA, 1980.

[213] B. Patterson and A. E. Wood, "Rodents from the deseadan oligocene of Bolivia and the relationships of the Caviomorpha," Bulletin of the Museum of Comparative Zoology at Harvard, vol. 149, pp. 371-543, 1982.

[214] A. R. Wyss, J. J. Flynn, M. A. Norell et al., "South America's earliest rodent and recognition of a new interval of mammalian evolution," Nature, vol. 365, no. 6445, pp. 434-437, 1993.

[215] M. G. Vucetich, D. H. Verzi, and J.-L. Hartenberger, "Review and analysis of the radiation of the South American Hystricognathi (Mammalia, Rodentia)," Comptes Rendus de l'Académie des Sciences-Series IIA: Earth and Planetary Science, vol. 329, no. 10, pp. 763-769, 1999.

[216] O. Heidmann, C. Vernochet, A. Dupressoir, and T. Heidmann, "Identification of an endogenous retroviral envelope gene with fusogenic activity and placenta-specific expression in the rabbit: a new "syncytin" in a third order of mammals," Retrovirology, vol. 6, article 107, 2009.

[217] J.-J. Jaeger, C. Denys, and B. Coiffait, "New Phiomorpha and Anomaluridae from the late Eocene of North-West Africa: phylogenetic implications," in Evolutionary Relationships among Rodents, W. P. Luckett and J.-L. Hartenberger, Eds., vol. 92, pp. 567-588, Plenum Press, New York, NY, USA, 1985.

[218] M. A. Nedbal, R. L. Honeycutt, and D. A. Schlitter, "Higherlevel systematics of rodents (Mammalia, Rodentia): evidence from the mitochondrial 12S rRNA gene," Journal of Mammalian Evolution, vol. 3, no. 3, pp. 201-237, 1996.

[219] D. Huchon, F. M. Catzeflis, and E. J. P. Douzery, "Variance of molecular datings, evolution of rodents and the phylogenetic affinities between Ctenodactylidae and Hystricognathi," Proceedings of the Royal Society B: Biological Sciences, vol. 267, no. 1441, pp. 393-402, 2000.

[220] T. Martin, "African origin of caviomorph rodents is indicated by incisor enamel microstructure," Paleobiology, vol. 20, no. 1, pp. 5-13, 1994.

[221] A. Mess, B. Mohr, and T. Martin, "Transformations in the stem species pattern of hystricognath Rodentia and the climatic change in the Eocene to Late Oligocene time interval," Mitteilungen aus dem Museum für Naturkunde, Zoologische Reihe, vol. 77, pp. 193-206, 2001.

[222] A. M. Mess and A. M. Carter, "Evolution of the interhaemal barrier in the placenta of rodents," Placenta, vol. 30, no. 10, pp. 914-918, 2009.

[223] C. Kanashiro, T. C. Santos, M. A. Miglino, A. M. Mess, and A. M. Carter, "Growth and development of the placenta in the capybara (Hydrochaeris hydrochaeris)," Reproductive Biology and Endocrinology, vol. 7, article 57, 2009.

[224] M. A. Miglino, A. M. Carter, R. H. dos Santos Ferraz, and M. R. Fernandes Machado, "Placentation in the capybara (Hydrochaerus hydrochaeris), agouti (Dasyprocta aguti) and paca (Agouti paca)," Placenta, vol. 23, no. 5, pp. 416-428, 2002.

[225] H. W. Mossman, "The rabbit placenta and the problem of placental transmission," The American Journal of Anatomy, vol. 37, pp. 433-497, 1926.

[226] B. Fischer, P. Chavatte-Palmer, C. Viebahn, A. N. Santos, and V. Duranthon, "Rabbit as a reproductive model for human health," Reproduction, vol. 144, no. 1, pp. 1-10, 2012.
[227] R. H. Foote and E. W. Carney, "The rabbit as a model for reproductive and developmental toxicity studies," Reproductive Toxicology, vol. 14, no. 6, pp. 477-493, 2000.

[228] E. Eixarch, E. Hernandez-Andrade, F. Crispi et al., "Impact on fetal mortality and cardiovascular Doppler of selective ligature of uteroplacental vessels compared with undernutrition in a rabbit model of intrauterine growth restriction," Placenta, vol. 32, no. 4, pp. 304-309, 2011.

[229] Z.-X. Fan, Y. Lu, L. Deng et al., "Placenta- versus bone-marrowderived mesenchymal cells for the repair of segmental bone defects in a rabbit model," FEBS Journal, vol. 279, no. 13, pp. 2455-2465, 2012.

[230] A. Tarrade, E. Lecarpentier, S. Gil et al., "Analysis of placental vascularization in a pharmacological rabbit model of IUGR induced by l-NAME, a nitric oxide synthase inhibitor," Placenta, vol. 35, no. 4, pp. 254-259, 2014.

[231] J. F. Larsen, "Electron microscopy of the chorioallantoic placenta of the rabbit: I. The placental labyrinth and the multinucleated giant cells of the intermediate zone," Journal of Ultrasructure Research, vol. 7, no. 5-6, pp. 535-549, 1962.

[232] S. Tavaré, C. R. Marshall, O. Will, C. Soligo, and R. D. Martin, "Using the fossil record to estimate the age of the last common ancestor of extant primates," Nature, vol. 416, no. 6882, pp. 726729, 2002.

[233] F. S. Szalay and E. Delson, Evolutionary History of the Primates, Academic Press, New York, NY, USA, 1979.

[234] B. F. Koop, D. A. Tagle, M. Goodman, and J. L. Slightom, "A molecular view of primate phylogeny and important systematic and evolutionary questions," Molecular Biology and Evolution, vol. 6, no. 6, pp. 580-612, 1989.

[235] M. Goodman, D. A. Tagle, D. H. A. Fitch et al., "Primate evolution at the DNA level and a classification of hominoids," Journal of Molecular Evolution, vol. 30, no. 3, pp. 260-266, 1990.

[236] J. P. Hill, “The developmental history of the primates," Philosophical Transactions of the Royal Society B: Biological Sciences, vol. 221, pp. 45-178, 1932.

[237] W. P. Luckett, "Comparative development and evolution of the placenta in primates," Contributions to Primatology, vol. 3, pp. 142-234, 1974.

[238] W. P. Luckett, "Cladistic relationships among primate higher categories: evidence of the fetal membranes and placenta," Folia Primatologica, vol. 25, no. 4, pp. 245-276, 1976.

[239] B. F. King, "The fine structure of the placenta and chorionic vesicles of the bush baby, Galago crassicaudata," American Journal of Anatomy, vol. 169, no. 1, pp. 101-116, 1984.

[240] H.-J. Merker, D. Bremer, H.-J. Barrach, and R. Gossrau, "The basement membrane of the persisting maternal blood vessels in the placenta of Callithrix jacchus," Anatomy and Embryology, vol. 176, no. 1, pp. 87-97, 1987.

[241] T. N. Blankenship, A. C. Enders, and B. F. King, “Trophoblastic invasion and modification of uterine veins during placental development in macaques," Cell and Tissue Research, vol. 274, no. 1, pp. 135-144, 1993.

[242] A. C. Enders, K. C. Lantz, P. E. Peterson, and A. G. Hendrickx, "From blastocyst to placenta: the morphology of implantation in the baboon," Human Reproduction Update, vol. 3, no. 6, pp. 561-573, 1997.

[243] A. C. Enders, T. N. Blankenship, A. T. Fazleabas, and C. J. P. Jones, "Structure of anchoring villi and the trophoblastic shell in the human, baboon and macaque placenta," Placenta, vol. 22, no. 4, pp. 284-303, 2001. 
[244] E. D. Albrecht, T. W. Bonagura, D. W. Burleigh, A. C. Enders, G. W. Aberdeen, and G. J. Pepe, "Suppression of extravillous trophoblast invasion of uterine spiral arteries by estrogen during early baboon pregnancy," Placenta, vol. 27, no. 4-5, pp. 483-490, 2006.

[245] N. S. Sunderland, S. E. Thomson, S. J. Heffernan et al., "Tumor necrosis factor $\alpha$ induces a model of preeclampsia in pregnant baboons (Papio hamadryas)," Cytokine, vol. 56, no. 2, pp. 192199, 2011.

[246] A. C. Enders and T. N. Blankenship, "Interstitial trophoblast cells: an enigmatic and variable component of the developing macaque placenta," Placenta, vol. 33, no. 9, pp. 672-676, 2012.

[247] V. H. J. Roberts, J. P. Räsänen, M. J. Novy et al., "Restriction of placental vasculature in a non-human primate: a unique model to study placental plasticity," Placenta, vol. 33, no. 1, pp. 73-76, 2012.

[248] R. D. Martin, "The evolution of human reproduction: a primatological perspective," American Journal of Physical Anthropology, vol. 134, supplement 45, pp. 59-84, 2007.

[249] K. S. Ludwig, "A further contribution to the structure of the gorilla placenta," Acta Anatomica, vol. 46, pp. 304-310, 1961.

[250] H. Soma, "Notes on the morphology of the chimpanzee and orang-utan placenta," Placenta, vol. 4, no. 3, pp. 279-290, 1983.

[251] E. Winterhager, P. Kaufmann, and R. Gruemmer, "Cell-cellcommunication during placental development and possible implications for trophoblast proliferation and differentiation," Placenta, vol. 21, no. 1, pp. S61-S68, 2000.

[252] P. Kaufmann, S. Black, and B. Huppertz, "Endovascular trophoblast invasion: implications for the pathogenesis of intrauterine growth retardation and preeclampsia," Biology of Reproduction, vol. 69, no. 1, pp. 1-7, 2003.

[253] D. Cavanagh, P. S. Rao, R. A. Knuppel, U. Desai, and J. U. Balis, "Pregnancy-induced hypertension: development of a model in the pregnant primate (Papio anubis)," American Journal of Obstetrics \& Gynecology, vol. 151, no. 7, pp. 987-999, 1985.

[254] D. M. Nelson, P. E. Swanson, B. B. Davison, G. B. Baskin, and A. C. Enders, "Ontogenetic and phylogenetic evaluation of the presence of fibrin-type fibrinoid in the villous haemochorial placenta," Placenta, vol. 18, no. 7, pp. 605-608, 1997.

[255] E. D. Albrecht, J. S. Babischkin, and G. J. Pepe, "Regulation of placental villous angiopoietin-1 and -2 expression by estrogen during baboon pregnancy," Molecular Reproduction and Development, vol. 75, no. 3, pp. 504-511, 2008.

[256] K. van Calsteren, R. Devlieger, L. de Catte et al., "Feasibility of ultrasound-guided percutaneous samplings in the pregnant baboon: a model for studies on transplacental transport," Reproductive Sciences, vol. 16, no. 3, pp. 280-285, 2009.

[257] T. G. Golos, G. I. Bondarenko, S. V. Dambaeva, E. E. Breburda, and M. Durning, "On the role of placental major histocompatibility complex and decidual leukocytes in implantation and pregnancy success using non-human primate models," The International Journal of Developmental Biology, vol. 54, no. 2-3, pp. 431-443, 2010.

[258] G. I. Bondarenko, M. Durning, and T. G. Golos, "Immunomorphological changes in the rhesus monkey endometrium and decidua during the menstrual cycle and early pregnancy," American Journal of Reproductive Immunology, vol. 68, no. 4, pp. 309-321, 2012.

[259] L. A. Cox, C. Li, J. P. Glenn et al., "Expression of the placental transcriptome in maternal nutrient reduction in baboons is dependent on fetal sex," Journal of Nutrition, vol. 143, no. 11, pp. 1698-1708, 2013.
[260] P. O. Favaron, J. C. Morini Jr., A. M. Mess, M. A. Miglino, C. E. Ambr, and C. E. Ambrósio, "Placentation and fetal membrane development in the South American coati, Nasua nasua (Mammalia, Carnivora, Procyonidae)," Reproductive Biology and Endocrinology, vol. 12, article 57, 2014. 

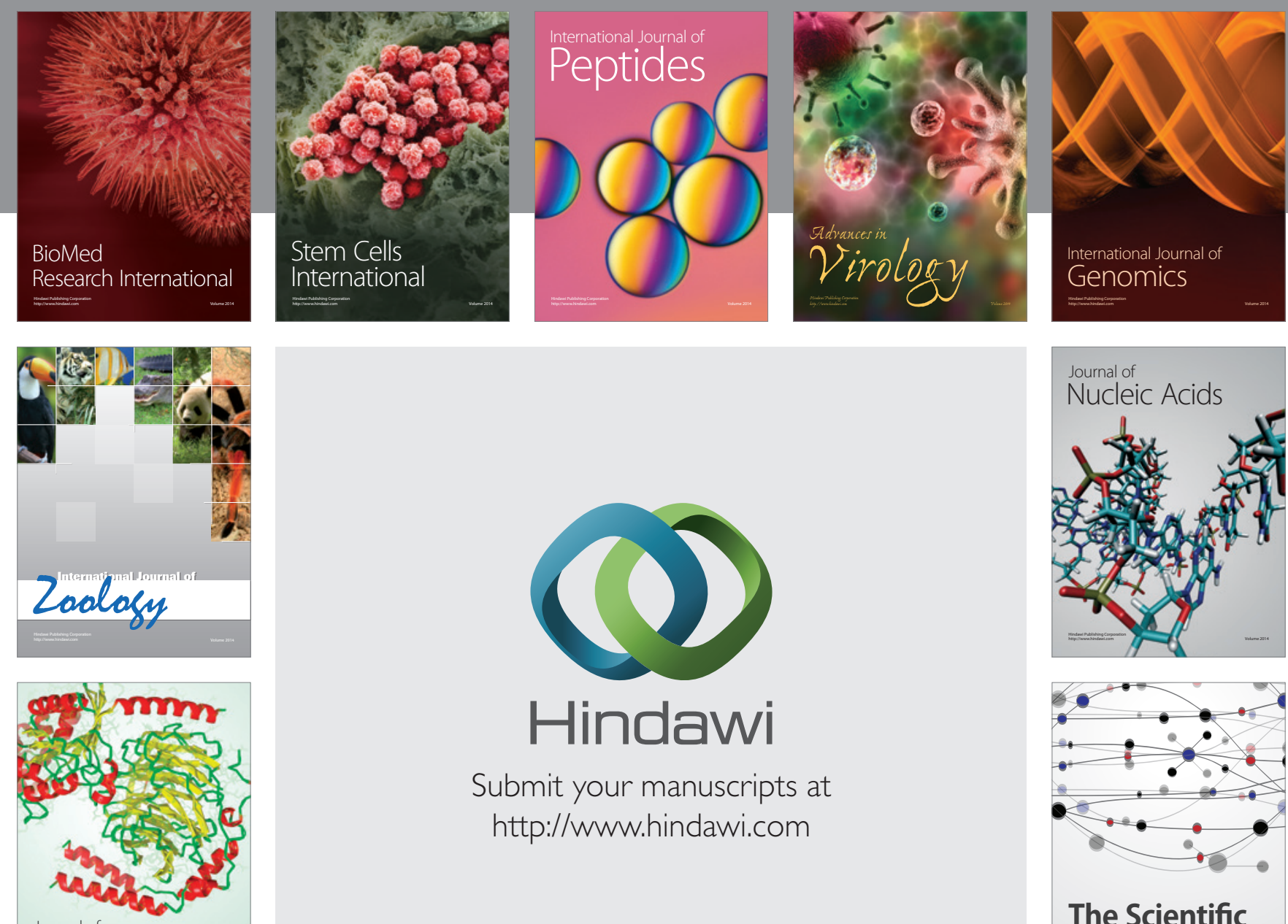

Submit your manuscripts at

http://www.hindawi.com

Journal of
Signal Transduction
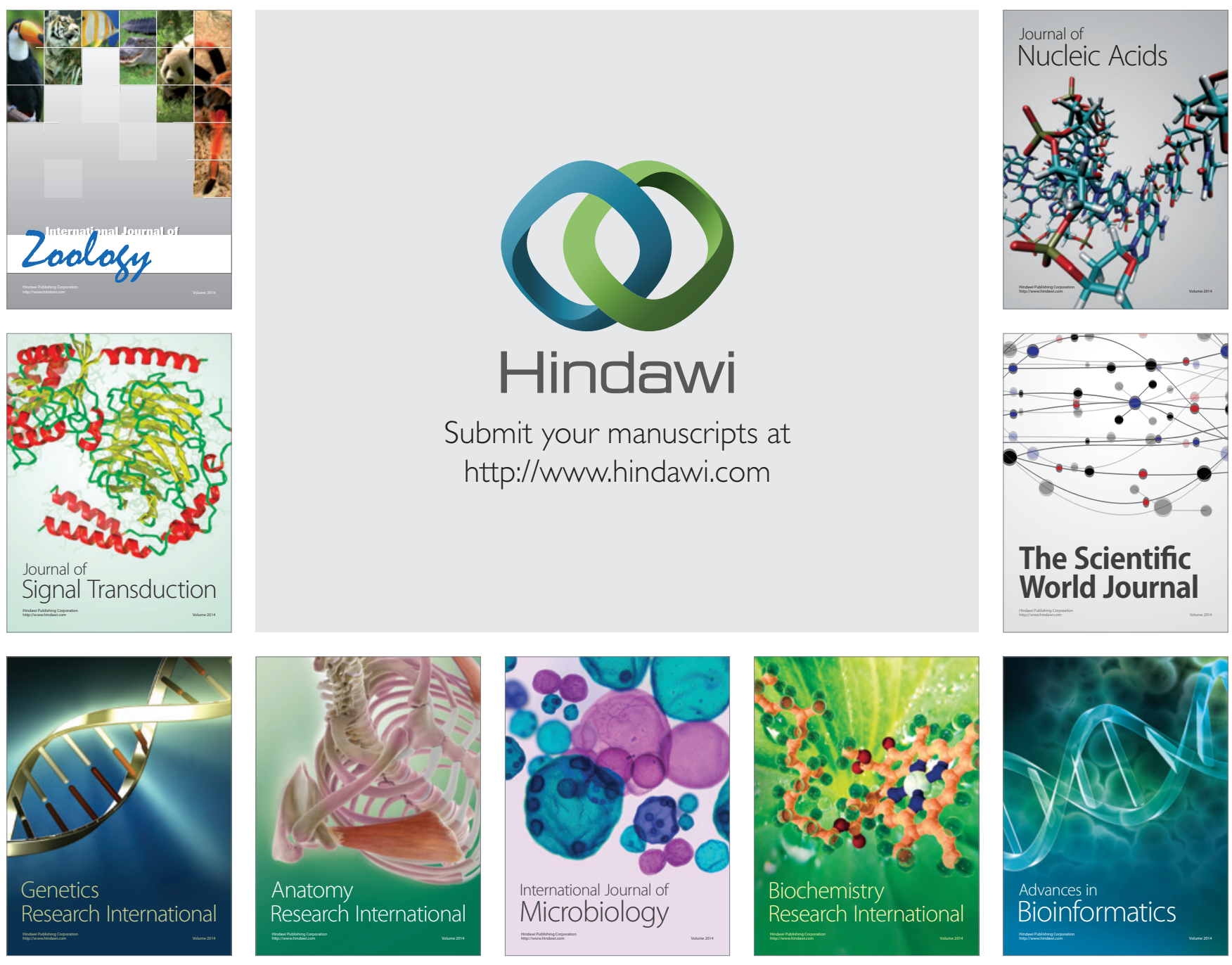

The Scientific World Journal
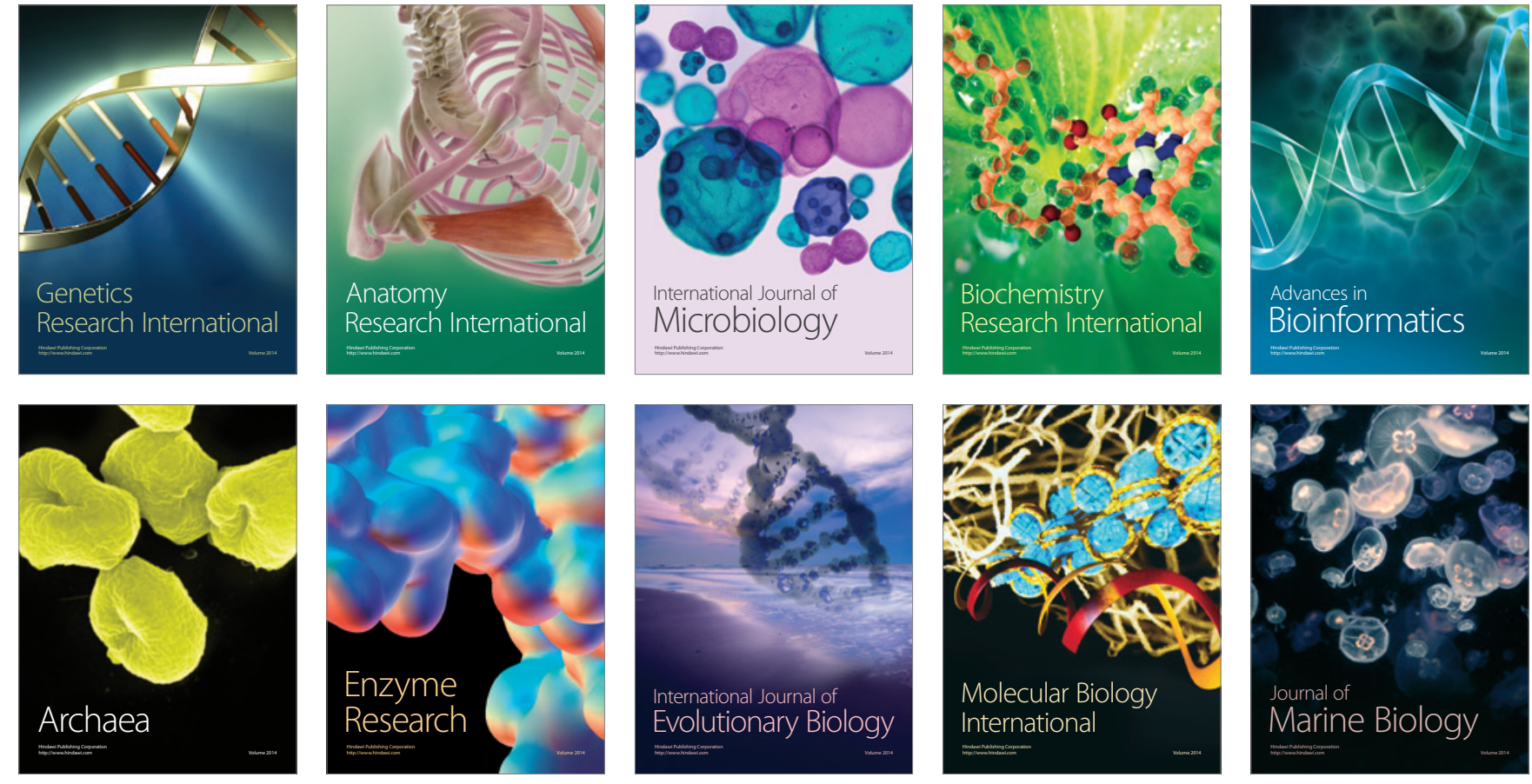